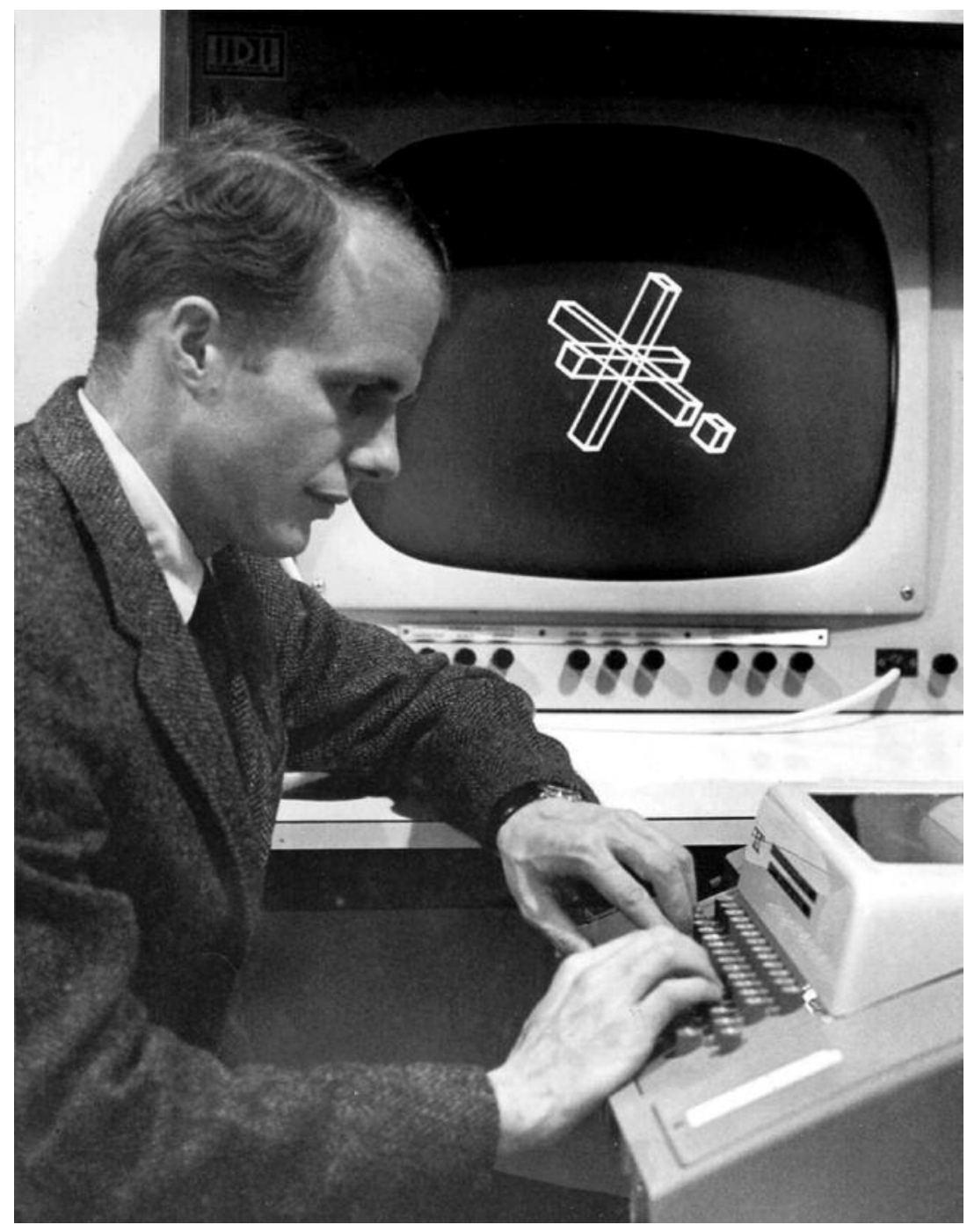

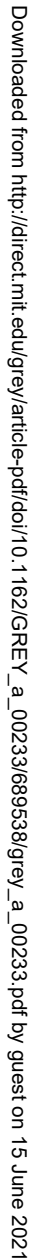

John Warnock and an

IDI graphical display unit,

University of Utah, 1968.

Courtesy Salt Lake City

Deseret News. 


\section{The Random-Access Image: Memory and the History of the Computer Screen}

\section{JACOB GABOURY}

A memory is a means for displacing in time various events which depend upon the same information.

一J. Presper Eckert Jr. ${ }^{1}$

When we speak of graphics, we think of images. Be it the windowed interface of a personal computer, the tactile swipe of icons across a mobile device, or the surreal effects of computer-enhanced film and video games-all are graphics. Understandably, then, computer graphics are most often understood as the images displayed on a computer screen. This pairing of the image and the screen is so natural that we rarely theorize the screen as a medium itself, one with a heterogeneous history that develops in parallel with other visual and computational forms. ${ }^{2}$ What then, of the screen? To be sure, the computer screen follows in the tradition of the visual frame that delimits, contains, and produces the image. ${ }^{3}$ It is also the skin of the interface that allows us to engage with, augment, and relate to technical things. ${ }^{4}$ But the computer screen was also a cathode ray tube (CRT) phosphorescing in response to an electron beam, modified by a grid of randomly accessible memory that stores, maps, and transforms thousands of bits in real time. The screen is not simply an enduring technique or evocative metaphor; it is a hardware object whose transformations have shaped the material conditions of our visual culture.

The computer screen is a relatively recent invention and is by no means essential to the concept of computation itself. Some form of output is necessary to make meaningful the calculation of a computational machine, but the screen is only one of many possible media forms that output can take. Yet in our contemporary digital media landscape the screen is ubiquitous—so much so that it is often taken for granted in all forms of computational interaction. As Nick Montfort suggests, "the screen is often portrayed as an essential aspect of all creative and communicative computing - a fixture, perhaps even a basis, for new media." ${ }^{5}$ This ubiquity has led to a "screen essentialist" assumption about computational 
systems, whereby the screen stands in for, and thereby occludes, the deeper workings of the computer itself. Yet, while we should not assume the screen exists as a pervasive feature of all machines in the history of computing, we likewise cannot discount the multiple and changing roles screens have played in the development of computational media over the past seventy years and the diverse forms the screen takes as it moves through the history of computing.

Prior to the 1970s, there were no computer screens as we know them now, and until the 1980s the vast majority of computational output was in the form of print terminals and teletypewriters. ${ }^{6}$ What few screen-based computergenerated images did exist had to be rigged for display using a variety of cathode ray technologies, as standard methods for interactive display did not yet exist. Despite the prevalence of screen technologies for televisual and cinematic images, these could not be readily adapted for use with computational technology because computer graphics, unlike film and television, do not begin as images. ${ }^{7}$ Rather, they begin as numerical data sets consisting of simple geometric primitives: coordinate points connected by vector lines to form simple wireframe objects. As such, the first screens for computer graphics were adapted from radar or oscilloscope tubes and modified to function as vector-based calligraphic or random-scan displays. Experiments into raster displays did not begin until the late 1960s, driven by a desire to simulate realistic opacity in computergenerated objects for real-time interaction. ${ }^{8}$ While the need for raster displays in the production of shaded graphics was one of the earliest concerns at pioneering research centers like MIT and the University of Utah, the hardware of the 1960s was not capable of computing and translating the massive amount of graphical data needed for real-time interaction. ${ }^{9}$ Real-time graphics would require new hardware forms that could supplement the general-purpose computer in its handling of graphical data, augmenting its calculations with the addition of a randomly accessible grid of graphical memory that contained a modifiable bitmap of each individual image frame-what would come to be known as a "frame buffer."

What may at first appear a minor technology is in fact one of the key graphical developments of the twentieth century, as it allowed for the first time the interactive manipulation of individual points of light on a screen. In doing so, it triggered an industrial-scale shift from vector to raster graphics over the course of the 1970s, leading to the familiar pixel-based computer screens used in all contemporary digital displays. More important, perhaps, the frame buffer reveals a material connection between image and memory in digital systems, offering new insights into the temporality of computation as a visually mediated practice. If the screen is the site at which a wide range of graphical traditions meet, 


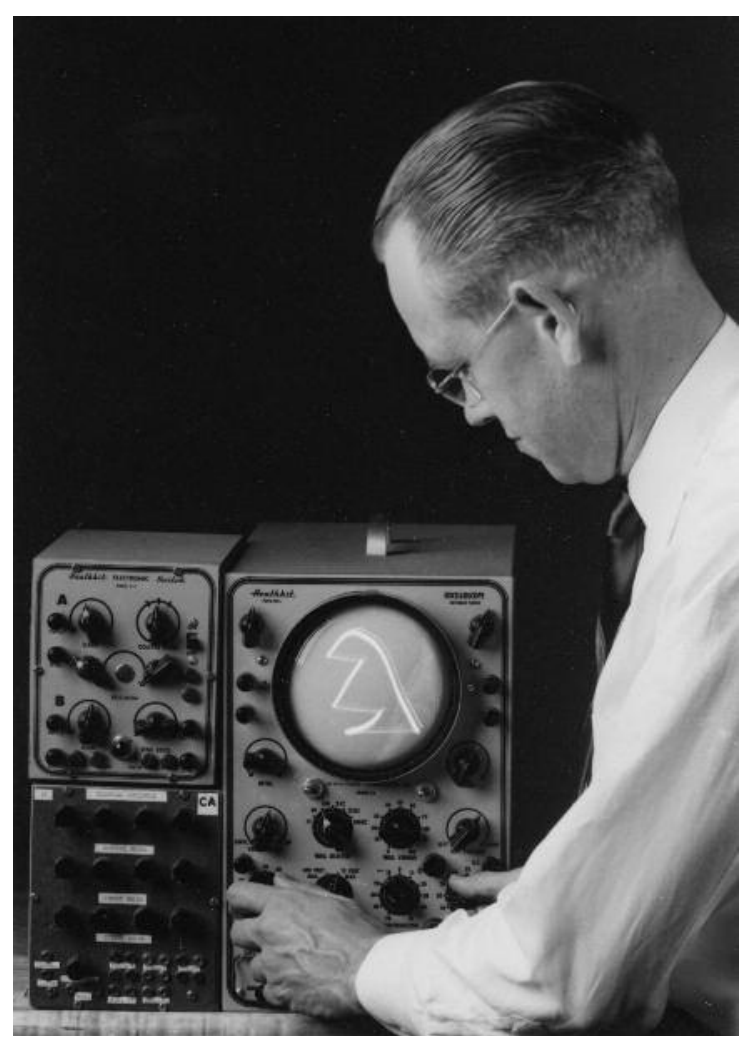

Ben Laposky with modified

oscilloscope, 1952. Courtesy

the Sanford Museum and

Planetarium, Cherokee, IA.

and the object through which all graphics are mediated, then the frame buffer is the graphical object that made possible a new form of screen image. In doing so the frame buffer comes to transform the material and ontological basis of the screen as a platform through which graphical data are filtered and understood, and demonstrates the ways in which the formal (i.e., technical) qualities of the screen affect the aesthetic and material shape that computer graphics come to take.

Line

In 1950 Ben Laposky of Cherokee, Iowa, began experimenting with the display screen of a cathode ray oscilloscope in an attempt to capture the pulsating abstract forms produced through the generation and manipulation of sine waves. Laposky, a trained mathematician, artist, draftsman, and World War II veteran, described this practice alternately as a form of "painting with light" and as a kind of visual music produced through the orchestration of electronic pulses across the screen of the CRT. ${ }^{10}$ He named the resulting forms "Oscillons," and over the course of the 1950s his work evolved into a complex technical practice involving "as many as 70 different settings of controls on the oscilloscope and of other combinations of input waveform generators, amplifiers, modulating circuits and so on."11 Laposky not only manipulated the settings of the oscilloscope to produce these desired effects; he also designed and constructed a wide range of electronic instruments to supplement and augment the oscilloscope's signal. While Laposky's Oscillons clearly differ from later graphical image practices in his use of analog signals to construct abstract forms, his swirling images anticipate the three-dimensional graphical objects that would be developed almost two decades later. As Laposky suggests,

While giving impressions of sweeping rhythms, the pulsating trace of the oscillating electron beam reveals their formation. Like other types of kinetic art, they involve the factor of time, in addition to giving an illusion of three dimensions on a two-dimensional surface. Some of the Oscillons have an almost sculptural quality. Because of the highly-contrasted, non-illuminated background of an oscilloscope screen . . . they may seem to be images of luminescent moving masses . . . suspended in space. ${ }^{12}$

In 1952 Laposky debuted his Oscillons at the Sanford Museum in Cherokee, 
Opposite, top: Oscilloscope with camera attachment. From Ben F. Laposky, "Oscillons: Electronic Abstractions," Leonardo (October 1969).

Opposite, bottom: Charactron extruded beam CRT diagram. Courtesy the Science Service Historical Image Collection, Smithsonian Institution.

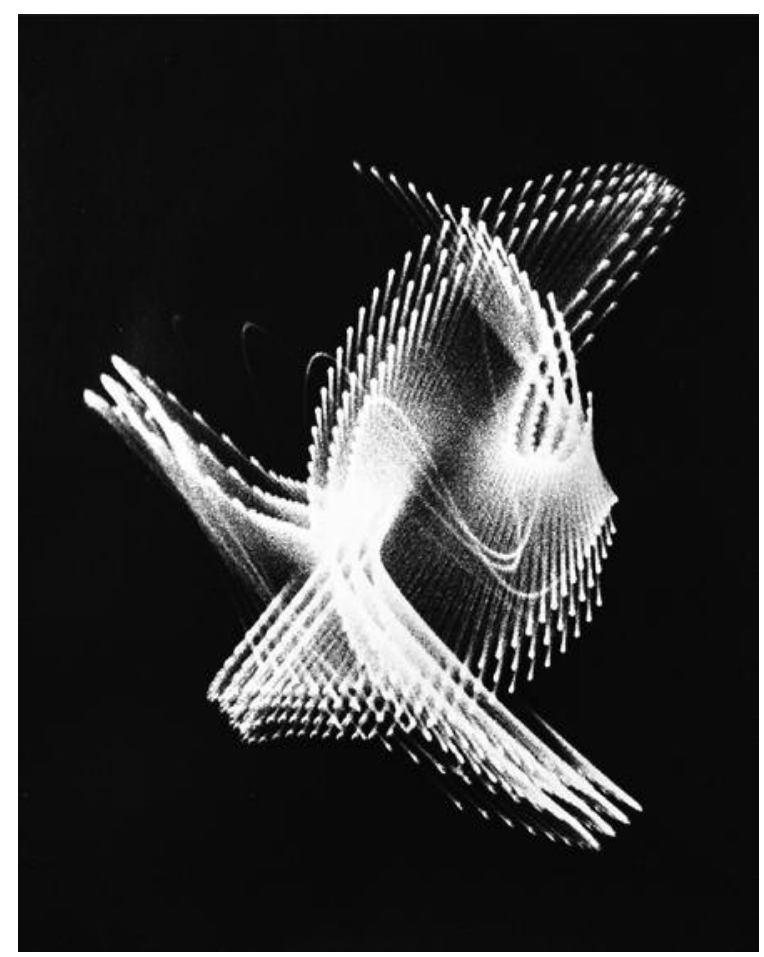

Iowa, to great acclaim, and the show went on to tour the United States and Europe from 1952 to $1961 .^{13}$

These images offer a compelling predecessor to later research into computer graphics, and are part of a long lineage of artistic experimentation with computational technology beginning in the immediate postwar era. ${ }^{14}$ Yet the formal and technical structure of Laposky's Oscillons differs wildly from that of contemporary computer-generated images, in large part due to the material specificity of the screens on which they were produced and the medium in which they were captured. Unlike contemporary graphics, they are not the result of the precise calculation of clearly defined geometries suspended in Euclidian space but are etchings of the interplay of analog electrical signals moving and transforming over time. Likewise, the images Laposky produced could not be printed or downloaded for storage and display-as is common with contemporary systems-because in 1952 there were no image file formats to capture the graphical output of a screen. To record his Oscillons, Laposky resorted to a much older visual form: photography. Using a camera stand attached to the base of an oscilloscope frame and adjusted to the desired distance from the viewing screen, Laposky photographed the waveforms in a darkened room, adjusting the exposure time to produce the desired effect. The resulting images straddle multiple media forms-a visual cluster held together by an assortment of technologies at once electronic and mechanical, both material and ephemeral. ${ }^{15}$

These swirling masses of light were formed at the intersection of photography and the cathode ray oscilloscope-an old medium capturing but a glimpse of the new. Yet, as strange and distant as the resulting Oscillons may seem, they are exemplary of an extended period from the late 1940s to the mid-1970s in which a bizarre patchwork of techniques and technologies formed the material and historical condition for the development of contemporary computer screens and digital imaging technologies.

\section{Screen}

The visual logic of this early period is dominated by the vector line. Until the 1970s, few computers could produce graphics more complex than simple line drawings, and early graphics were thus largely composed of simple shapes traced onto the screen of a CRT. In many ways the CRT is one of the most 

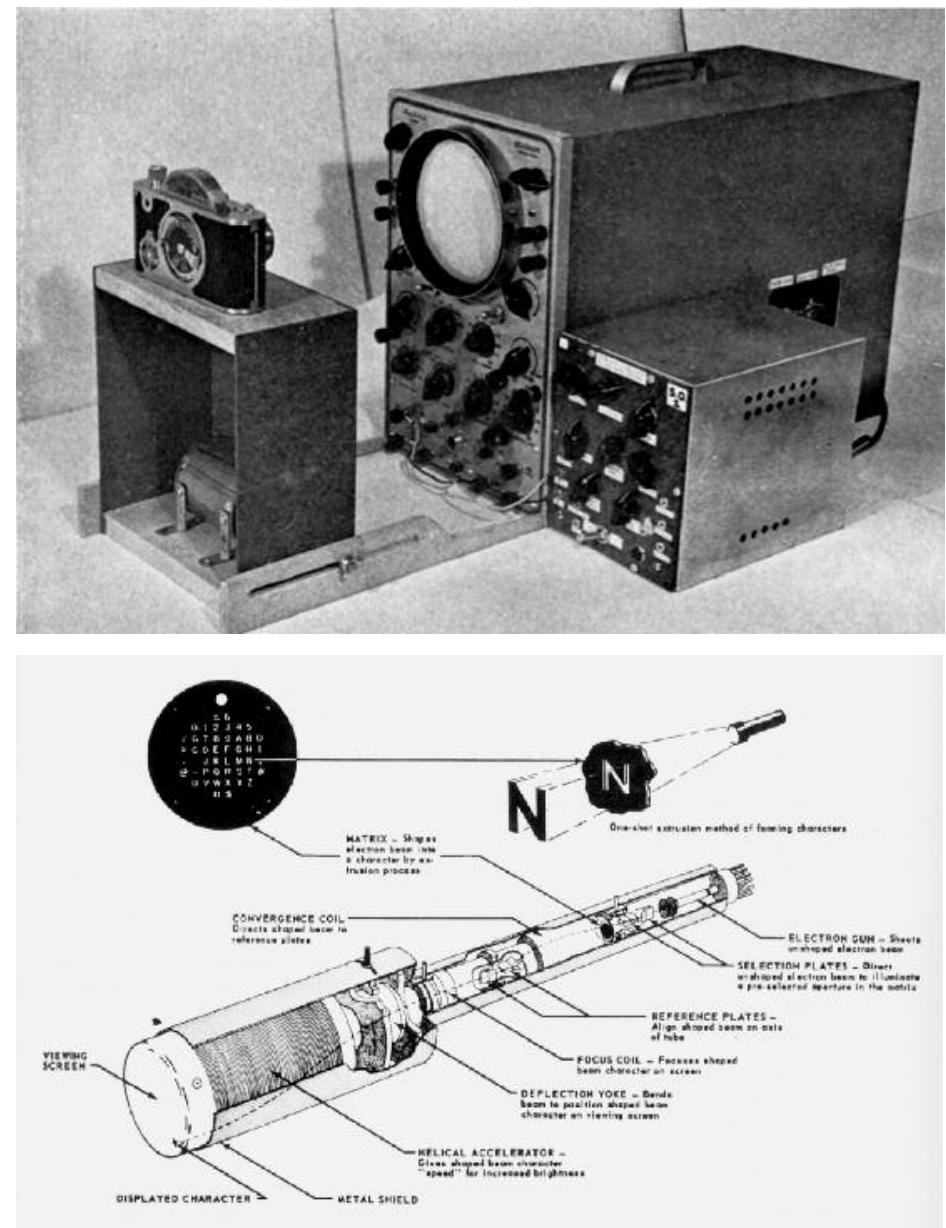

emblematic and ubiquitous visual technologies of the twentieth century: conceived and developed in its first thirty years, commercialized and widely distributed in the postwar era, and reaching near ubiquity by the close of the century. ${ }^{16}$ Yet the rapid technical obsolescence of the CRT brought on by the popularization of liquid-crystal and plasma displays in the early 2000s revealed these screens as much more than an inert platform whose transformations were limited to progressive changes in scale and definition..$^{17}$ No longer state of the art, CRTs have become emblematic of the cycle of technological obsolescence, the crisis of electronic waste, and the challenge of technological preservation for media that rely on the material specificity of their form. ${ }^{18}$ Increasingly scarce, the CRT has become a dead media artifact whose specificity must be accounted for if we are to understand its influence on our visual culture..$^{19}$

In a CRT, an electron gun fires patterns or shapes at the face of the tube, which is coated on the inside with a layer of phosphors. These phosphors glow in response to the electrons, which creates a visible light for a moment before fading or being refreshed by another pass of the beam. The image on the screen is thus not drawn all at once but is refreshed in a continuous pattern. By far the most common CRT display was the television screen, whose image is structured by hundreds of individual scan lines drawn by the electron gun as it slides from side to side across the screen. After each line, the beam is turned off and the gun resets its position at the start of the next line, continuing this process until it reaches the bottom of the screen, at which point it returns to its initial position to begin its scan again..$^{20}$ Yet this is not the only form the CRT takes, nor is it the only visual tradition from which we might draw the origins of the computer display. As should be clear from Laposky's Oscillons, there are many screen media that utilize CRT technology, including oscillography, radar, and ad hoc devices built for various forms of scientific visualization.

To give but one example, the most common CRT used throughout the 1950s 


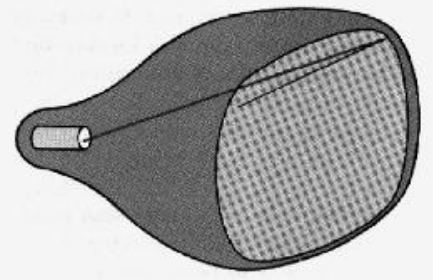

(a)

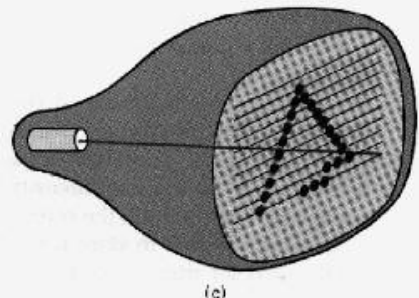

(c)

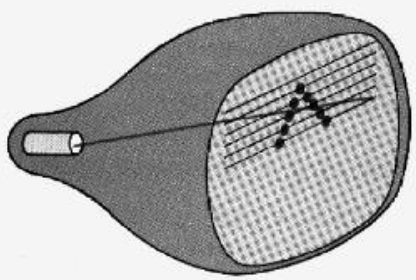

(b)

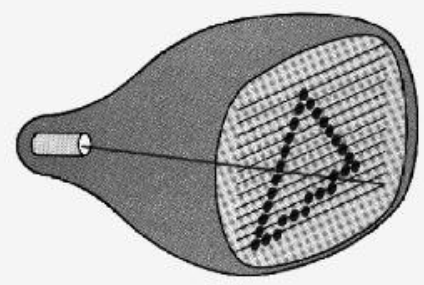

(c) Aircraft (Convair) in 1952, the Charactron was designed to display alphanumeric characters using a technique known as shaped or extruded beam projection. Unlike the regimented scan lines of a television CRT or the continuous curves of oscillography, the Charactron displayed images and text by deflecting its beam through a matrix mask with an array of sixty-four apertures in the shape of alphanumeric characters. In this way it could "punch out" the shape of the desired character onto the face of the tube using only a single beam of light. ${ }^{21}$ This system was originally designed for textual display, as the combinatory logic of alphanumeric systems allowed for most any word or number to be easily displayed, but was adapted for more explicitly graphical purposes by the early 1960s before falling out of use at the start of the 1970s. ${ }^{22}$ Many of the images produced by artists and researchers in this period at sites like AT\&T Bell Laboratories were the product of this unique screen technology, one that bears no more resemblance to our modern computer screens than do Laposky's oscilloscopes.

Given the multiple and heterogeneous forms the CRT takes, it can be difficult to identify a single techno-historical tradition from which to draw out the origins of the computer screen. The technology behind the CRT display was first conceived in the late nineteenth century by Karl Braun and subsequently developed by Vladimir Zworykin for use in television in the first three decades of the twentieth century. ${ }^{23}$ Zworykin's legacy looms large over the early history of the television set and the move toward commercialization begun in the 1930s. These early origins of the CRT and its development as a televisual technology have been well documented by film and television scholars; however, existing histories tend toward biography and often foreground television's strained relationship with cinematic media in the struggle over cultural dominance in the twentieth century. ${ }^{24}$ Missing is a larger discussion of the CRT as a technical object that functioned within a much broader media landscape, one whose significance is perhaps less cinematic than it is scientific or, at the very least, electronic. Not only is the CRT the material object that makes possible the first fifty years of televisual images; it is the basis for a wide range of nonrepresentational media built around the display and manipulation of electrical currents, the most significant of which are cathode ray oscilloscopes like those used by Laposky.

The oscilloscope is a type of electronic test instrument meant for the observation of constantly varying signal voltages. It serves to visualize electrical waveforms such that they may be analyzed for amplitude, frequency, and other 


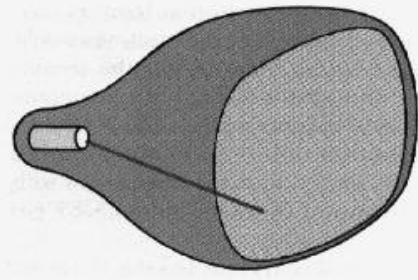

(a)

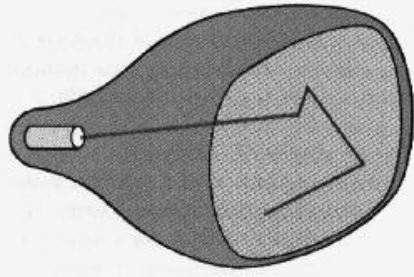

(c)

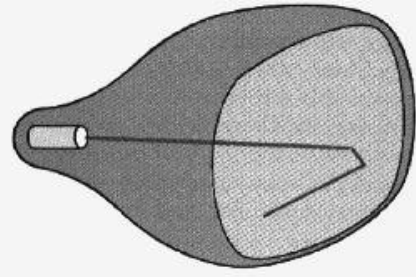

(b)

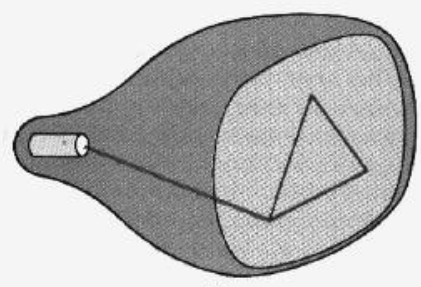

(d)

properties. ${ }^{25}$ Like the CRT itself, oscillography is one of many technologies born out of the massive growth in the electrical sciences during the nineteenth century, beginning with the development of electrical telegraphy. ${ }^{26}$ These techniques for understanding and manipulating electricity-mediated as they are by the electron beam of the CRT-intersect with the history of computer graphics at multiple points, marking several transformations in the emergent medium's visual logic. Here the oscilloscope is of particular interest for the significant ways in which it mechanically differs from the television CRT. Unlike the regimented sweep of the television scan line, the electron beam of an oscilloscope can be modified to trace lines of any shape or angle onto its screen. When used in the testing of constantly varying voltage signals, the oscilloscope deflects its electron beam using electrostatic force in a continual pattern; however, its display could also be modified to draw noncontinuous lines following a "calligraphic" pattern. In such a system the electron gun is pointed at a certain location, turned on, and moved from that $(x-y)$ coordinate to another point in a line or curve where it is turned off again. In this way an image can be painted or drawn on the face of the display. ${ }^{27}$ By modifying the computer's output into a signal that can be read by the oscilloscope's calligraphic display, researchers could take advantage of the continuous movement of the waveform to draw out simple shapes and letters using varying electrical signals. ${ }^{28}$

The advantage of these vector displays was their simplicity. Vector images comprise little more than a collection of vertices on an x-y coordinate plane and, as such, can be modified and transformed easily and with relatively little calculation. Vector graphics can also display smooth curves and have no difficulty with aliasing and other visual challenges that plagued raster graphics for decades. ${ }^{29}$ Yet vector graphics were extremely limited in other ways. The most glaring limitation of vector-based systems was their inability to scale in number and complexity without noticeably affecting the visibility of the image to be displayed. One of the main benefits of the oscilloscope was that, unlike a television screen that quickly scans the entire face of a CRT in a sequential line, the oscilloscope could move to draw and transform images at any point on its screen in real time. However, the drawback to this method was that it limited the speed at which the beam could operate. All cathode ray technology requires the image to be constantly refreshed in order to remain visible. If the electron beam does not refresh an image in time, the light of the screen will fade, producing a noticeable flicker. In early screens the speed at which an image could 
be refreshed scaled downward proportional to the size and complexity of the image. The more the electron beam had to write on the phosphor of the screen, the longer it took and the greater the delay before it could return to refresh the image. The more one tried to draw on the screen, the more pronounced the flicker would become and the less functional the image would be. ${ }^{30}$

Thus, while calligraphic displays were ideal for simple shapes, the oscilloscope CRT could not scale to accommodate the needs of graphics researchers or the emerging graphics industry. ${ }^{31}$ To accomplish complex, fully shaded, threedimensional images, researchers would need to find a way to adapt the raster scan technique of television - a goal that would prove no simple task given the unique structure and function of computer-generated images and the challenge of moving from a visual system based on the sweeping vector line to the regimented grid of the raster and its pixelated display.

\section{Grid}

The grid is the operative visual technique of contemporary digital media technology. Found everywhere, it is most visible in the pixelated face of the contemporary computer screen. Of course, the grid is nothing new. Like so many mediating techniques, it can be traced back millennia and has been repeatedly engaged by scholars invested in its material and aesthetic form. ${ }^{32}$ Hannah Higgins, for example, follows the grid's appearance across a range of artistic, technological, and architectural practices, reaching back as far as the development of bricklaying and fishing nets during the eighth century BCE. ${ }^{33}$ As she shows, the grid can be found in the structure of maps, tablets, notation, type, and even in the network architecture of the modern Internet. The impulse behind this genealogy is, in part, a refusal of the supposition that the grid is an explicitly modern phenomenon, as Rosalind Krauss suggests in her 1979 essay "Grids." ${ }^{34}$ For Krauss the grid of modernist art is a pointed refusal of the naturalism that defined centuries of earlier artistic traditions. In contrast to earlier visual forms, the grid is "flattened, geometricized, ordered . . anti-natural, antimimetic, antireal. It is what art looks like when it turns its back on nature." ${ }^{35}$ Channeling Krauss, Higgins suggests "the modernist grid is an emblem of industry. It reflects standardization, mass production, and the newly smooth mechanics of transportation. In the modern imagination, in other words, the grid pits culture against nature and the body." ${ }^{6} 6$ The raster grid of the computer screen would appear to follow in this tradition, emblematic of the standardization of the image form by digitization.

In contrast, Bernhard Siegert argues convincingly that the grid's primary function is in fact an ordering of the world. Following Michel Foucault, he 
presses that, beyond its familiar perspectival, cartographic, or mathematical functions, the grid serves a third aesthetic and deictic function:

the grid serves to constitute a world of objects imagined by a subject. To speak with Heidegger, it is a Gestell or "enframing" aimed at the availability and controllability of whatever is thus conceived; it addresses and symbolically manipulates things that have been transformed into data. The grid, in short, is a medium that operationalizes deixis. It allows us to link deictic procedures with chains of symbolic operations that have effects in the real. Thus the grid is not only part of a history of representation, or of a history of procedures facilitating the efficient manipulation of data, but also of "a history of the different modes by which, in our culture, human beings are made into subjects.” 37

Yet not all grids function equally in this regard (or, at minimum, the particularity of each grid form enacts its own kind of ordering). The raster of the Stone Age fishing net differs in substantive ways from that of the distributed network, much as the grid of the Renaissance painter's screen differs from the grids of Piet Mondrian or Jasper Johns. We must distinguish the specificity of the technical forms that the grid takes even as we acknowledge its continuity as part of a larger cultural technique that structures or orders the world. This is not to be pedantic or abstruse but to draw out the ways in which techniques are reproduced over time through means both technical and cultural, in which seemingly universal structures come to reflect the specificity of a historical moment through a kind of transformative endurance. Nowhere in the history of graphics is this distinction more apparent than in the relationship between the television and the computer screen.

The primary obstacle in any effort to modify a raster scan television to accept computational data is one of time or sequence and, along with it, memory. The television, as it functioned in the 1960s, was an immediate, linear medium designed for the procedural transmission of image-based input scanned from the target plate of a television camera. It adopted the serial or sequential structure of film, though it did so not through the procession of photographic images on a strip of celluloid but through the procession of an electron beam across the face of a CRT. Unlike film, what most distinguished the television was its ability to transmit and display images and sounds in real time and without storage. ${ }^{38}$ Televisual images were not captured or calculated, they were scanned as signals and transmitted in a linear stream, line by line, appearing for a moment and then disappearing altogether, replaced with the next pass of the electron beam. While this served the function of television well, it did not lend itself to the 
display of computational images, which were produced through complex calculation, had no external temporality per se, and needed to be stored in memory to be accessible for interaction. Unlike all other screen media, computational images must linger, idle and accessible, until they are transformed through an interaction that, significantly, may begin at any point on the screen. At its heart, the incompatibility of the television's grid form with the demands of interactive computation marks the basic ontological concern for all computational systems; that is, the conversion of continuous or analog information into discrete and thereby actionable forms. Put simply: digitization. ${ }^{39}$ Thus, a mediating technology was necessary to modify the procedural logic of the analog television to accommodate the digital logic of random access. ${ }^{40}$ The solution was the development of a dedicated memory capable of storing and transforming graphical information apart from the memory of the general-purpose central processing unit. This device would come to be known as the "frame buffer."

\section{Buffer}

A frame buffer is nothing more than a piece of computer memory specialized for holding pictures. When using a frame buffer, the computer writes a single frame of video into memory as a bitmap..$^{41}$ It then begins to compute the next frame while, independently, the display device reads the current frame out of the buffer to display it. In this way the computer can separate calculation from display, storing visual data in memory as needed until it is changed or transformed through interaction.

The memory in a frame buffer differs from other forms of computer memory in that it is arranged as a two-dimensional array that maps directly onto the bits of the raster screen image. Ordinary random-access computer memory (RAM) stores everything in discrete pieces-bits at the lowest level. But pictures do not fit well in one-dimensional lists, so a frame buffer stores the picture divided up into rows and columns of what we now call pixels-a 2D array of memory locations. ${ }^{42}$ By mapping the image in this way, the frame buffer enables the rapid processing of graphical information that is, in turn, ordered for display, pushed into memory, and output onto the screen. By using a random-access form, the frame buffer models the calligraphic display without the material structure that enables the random movement of the electron beam across the screen of an oscilloscope CRT. It can thereby display shaded or half-tone images in the same manner as a television set while also allowing for quick and interactive access to that display via a light pen, mouse, or other input device. Since the bitmap of the screen is randomly accessible, it is not necessary to recalculate the entire screen when interacting with or transforming an area of the image, as the 


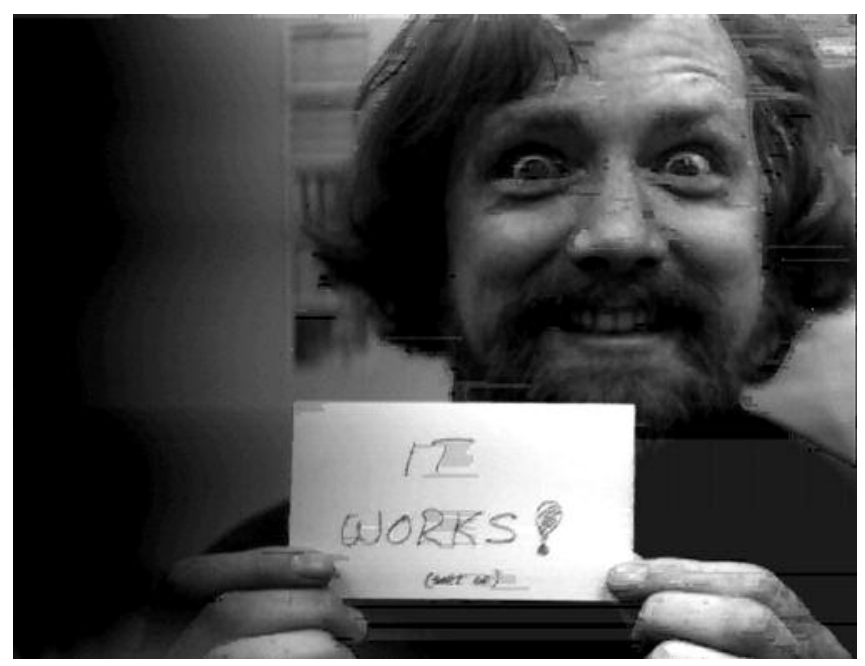

Early digital image of Richard Shoup, rendered on the SuperPaint system, April 1973. Courtesy the Richard G. Shoup Estate.

ing bits in the buffer. Thus, the frame buffer allows for random access to the procedural image, mapping the control structure of the grid onto the linear flow of the television screen through memory. ${ }^{43}$ This is the image made digital, the random-access image.

As is often the case with the development of computational technologies, the frame-buffer concept has no single origin. By the late 1960s, several research institutes had begun to develop experimental memory devices for graphical display on a raster screen, but the earliest functional frame buffer was likely a simple 3-bit paint program developed by Joan Miller at Bell Labs in 1969. ${ }^{44}$ Working from Miller's program, Bell engineers developed several functional raster systems under the direction of A. Michael Noll, and by 1970 they had a modified Picturephone system capable of producing real-time half-tone images on a raster display. ${ }^{45}$ The system used a technique known as drum storage, in which the writing of new graphical data into memory was contingent on the sequential speed and rotation of a physical drum that stored the raster grid. As such, the system could not truly be considered randomly accessible, but Noll saw little benefit in a separate addressable digital core storage for display data, believing that exponential growth in storage capacity would more than make up for the future needs of buffer storage. ${ }^{46}$

Thus, the first true frame buffer was not developed until 1972, when a young researcher at Xerox PARC named Richard Shoup began work on SuperPaint, an 8-bit paint system complete with interactive software interface and hardware frame buffer. ${ }^{47}$ Shoup called his system a "picture memory," and it allowed an artist to change the individual bits of a frame buffer at locations specified with a simulated paintbrush, creating a direct and immediate correspondence between electrical bits in memory and the physical phosphors on the TV screen. ${ }^{48}$ In this sense SuperPaint may be understood as the technical and intellectual predecessor to all modern paint and photo-editing software. One of the first images successfully produced by the frame buffer, in April 1973, was a black-and-white photograph of Shoup holding a note card that reads, "It works! (sort of)." 49

Shoup's SuperPaint marked a brief period of experimentation with digital paint systems and artistic applications for frame buffer technology at PARC. Working with a research team that included computer scientist Alvy Ray Smith and artist David DiFrancesco, Shoup considered the frame buffer a new artistic medium to be explored and saw PARC as an experimental space in which artists and technologists could meet to create new media forms. This period would be 
Right: One rack of Richard Shoup's SuperPaint system, containing the frame buffer, Xerox PARC, 1973. Courtesy the Richard G. Shoup Estate.
Opposite, left, top and bottom: Raster images of $100 \times 100$ and $512 \times 512$ pixels from the PIXURE system, University of Utah, 1967. From Chris Wylie et al., "Half-Tone Perspective Drawings by Computer," Proceedings of the November 14-16, 1967, Fall Joint Computer Conference (1967).

Opposite, right, top and bottom: Early resolution tests, University of Utah, 1968. Courtesy the Special Collections Department, J. Willard Marriott Library, University of Utah.

short lived, however, as in 1974 Xerox decided to abandon color graphics altogether, envisioning black-and-white as the future for the commercial office. ${ }^{50}$ In early 1975, Smith and DiFrancesco were let go as contractors at PARC. The pair immediately began a search for the next working frame buffer.

By 1975 the University of Utah had developed the first commercially available frame buffer system, which was produced, marketed, and sold by the program's spinoff enterprise, the Evans \&

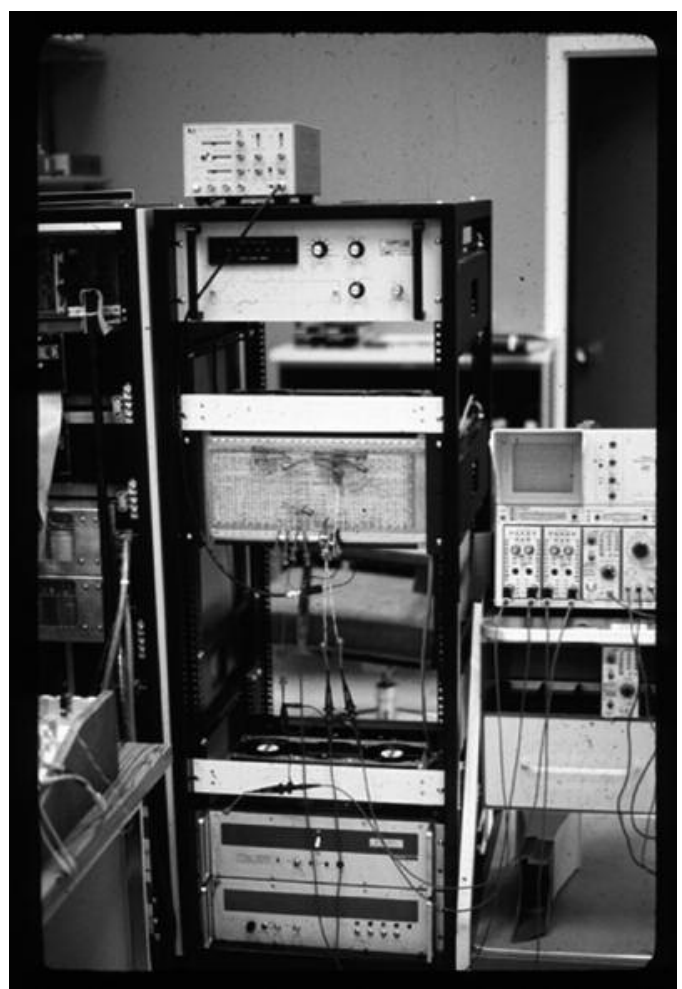

Sutherland Computer Corporation (E\&S). ${ }^{51}$ The E\&S buffer marks an important moment in the transition toward a commercially viable graphics industry, as hardware systems became available beyond university and government-sponsored research centers for the first time. Nonetheless, by the time of its release in the mid-1970s, researchers in Salt Lake City had been experimenting with raster graphics for almost a decade. As early as the Fall Joint Computer Conference of 1967, Chris Wylie, Gordon Romney, Alan Erdahl, and David Evans had published a paper describing methods for producing shaded half-tone perspective drawings by computer using an oscilloscope modified to accept data as horizontal scan lines from a FORTRAN IV algorithm called PIXURE. The system could produce simple shaded drawings of geometric shapes rendered at varying resolutions. ${ }^{52}$

This PIXURE hardware predates the concept of the frame buffer as a standalone object, but the images the system produced are nonetheless some of the earliest examples of shaded three-dimensional graphical objects. That said, due to the limitations of the available hardware and the lack of a standalone buffer, the images could not be displayed in real time. Instead they were calculated and rendered over the course of several minutes, such that all visual documentation required the mediation of long-exposure Polaroid photography, using light-tight devices that were physically attached to the screen of the CRT.

As with Laposky's Oscillons, these images could not be viewed in their entirety without the use of long exposure photography, which in a sense functioned as the memory of these early displays, separating the act of calculation from the process of representation. The amount of time each image took to be calculated depended largely on the complexity of the object, along with the desired resolution of the image. ${ }^{53}$ Yet, despite clear limitations in render speed and processing power, the research team believed that real-time movement and display for three-dimensional graphics was not far off, given the rapid develop- 

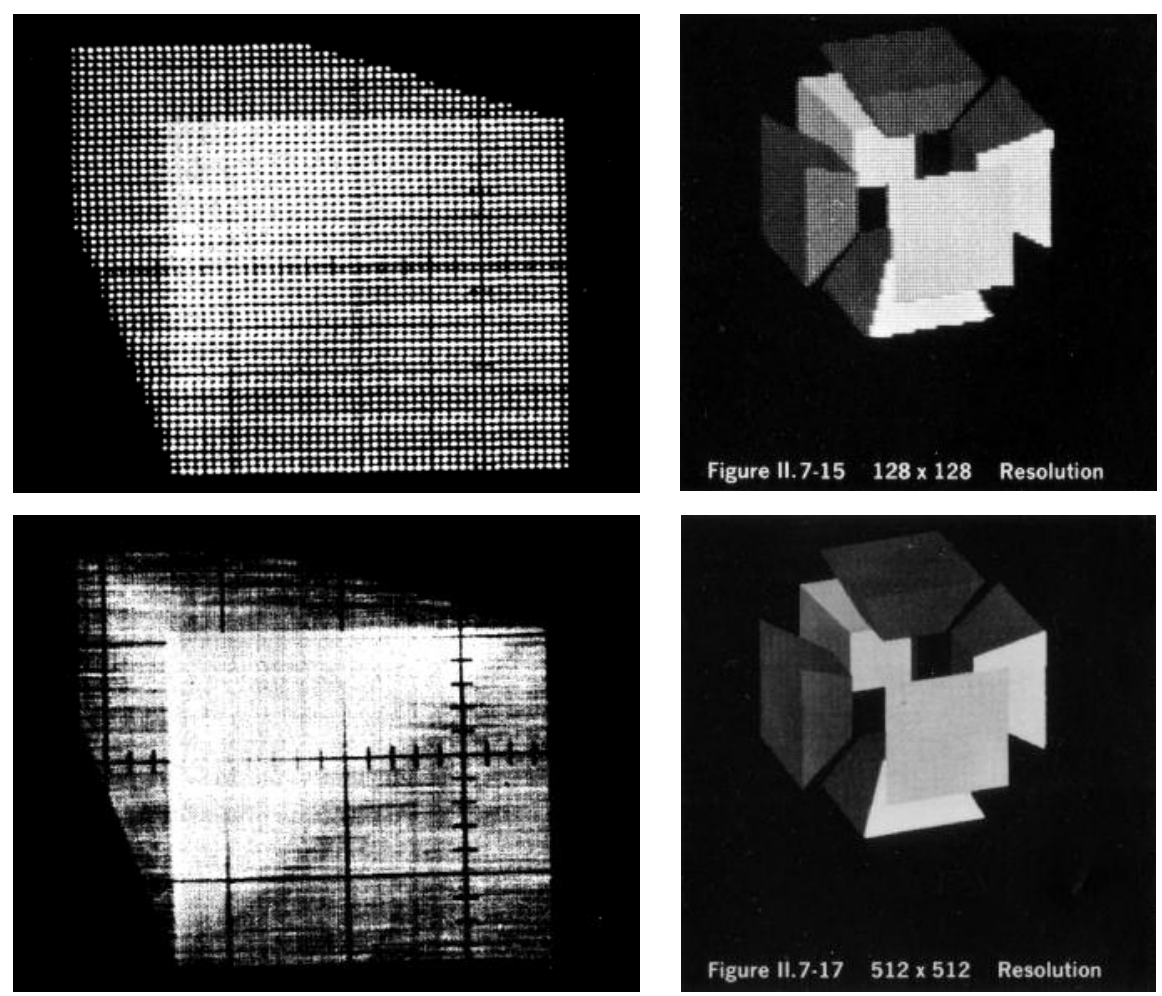

ment of efficient algorithms for hidden surface removal and the use of parallel computing to accomplish calculations for display. ${ }^{54}$

While the frame buffer concept was not clearly articulated until 1972, it had been in development alongside research into hidden surface removal, geometry, shading, and color at sites such as the University of Utah since as early as the mid-1960s. With the development of the E\&S frame buffer system, interactive images could finally be produced on a television screen in real time. ${ }^{55}$ Here, for the first time, was a system for interactive shaded graphics built for generalpurpose computing and available for purchase through the commercial market.

On hearing of the E\&S system, and with the goal of finding new institutional sponsors, Smith and DiFrancesco set out on a road trip from Silicon Valley to Salt Lake City in the hopes of continuing their research. What they found was a university with deep ties to the Department of Defense and little interest in funding artistic applications of their hardware. ${ }^{56}$ After one meeting with program director David Evans, the two were quickly turned away-but not before being given the name of Alexander Schure, a wealthy businessman from New York who had purchased "one of everything in sight" on a recent trip to E\&S, including the not-yet-delivered frame buffer. "He had animators from Hollywood making an animated film," Smith was told. "You can talk art with him." 57 Smith and DiFrancesco were soon on a plane to visit the New York Institute of Technology (NYIT) in Old Westbury, New York, on the North Shore of Long Island, where after an initial meeting with Schure they were quickly hired. Over the next five years NYIT served as the test bed for what would ultimately become the commercial computer animation industry. Driven by Schure's enthusiasm and generous funding, NYIT had already attracted prominent researchers from Utah and PARC, including Ed Catmull and Martin Newell. ${ }^{58}$ Schure's dream was to develop the first fully computer-animated feature film, and the team worked for years developing custom software called TWEEN, 
Top: "GRAPHICS" raster test,

University of Utah, 1968.

Courtesy the Special Collections

Department, J. Willard Marriott

Library, University of Utah.

Bottom: Evans \& Sutherland Computer Corporation. The video frame buffer (right) and an E\&S Picture System (left) used to display a Klein bottle, 1975. Courtesy the Special Collections Department, J. Willard Marriott Library, University of Utah.

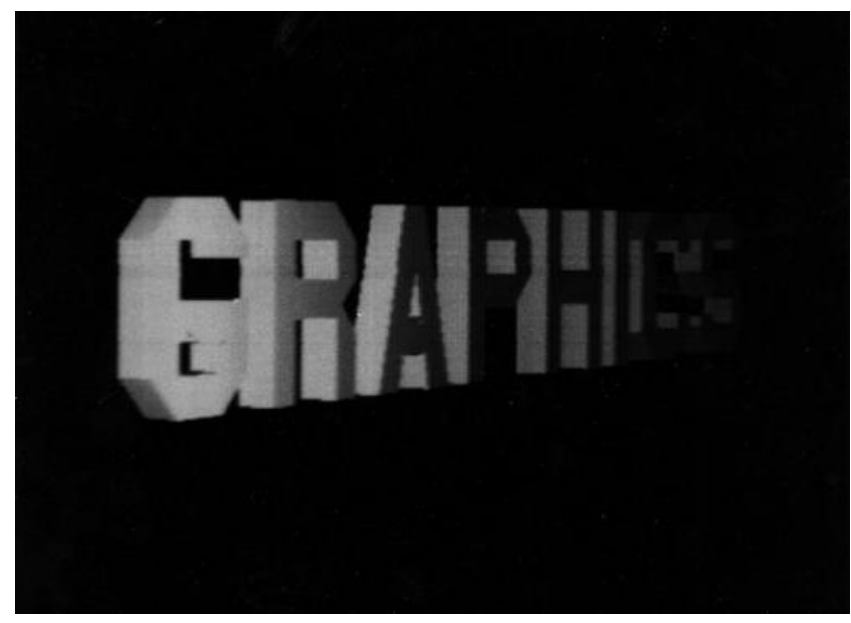

which they hoped would digitize the cell animation process and revolutionize the animation industry. ${ }^{59}$ Ultimately the system would prove too costly and ineffective, and the dream of a feature-length computeranimated film would go unrealized for almost twenty years. Nonetheless, NYIT served as an important test bed for Catmull, who would go on to lead the Industrial Light and Magic computer graphics division at LucasFilm and, with Alvy Ray Smith, found Pixar Animation Studios in $1986 .{ }^{60}$

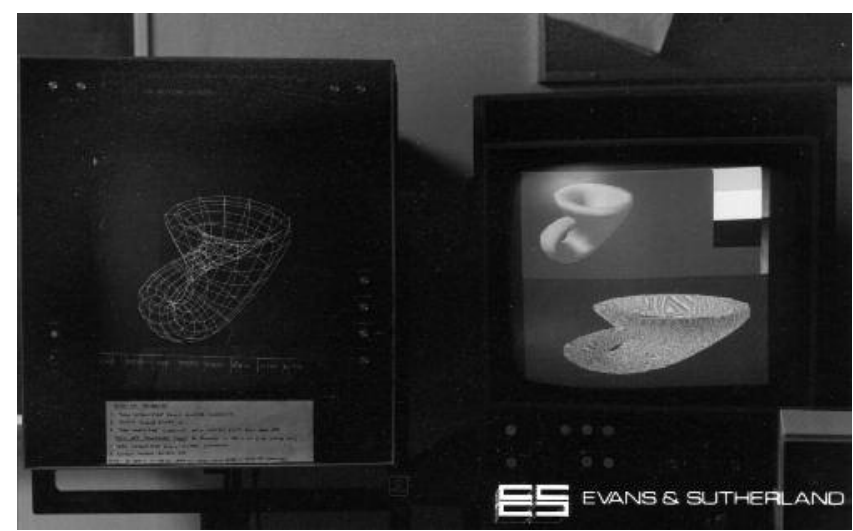

As the history of the NYIT computer graphics lab makes clear, the development of commercial frame buffer-enabled systems created new markets and new uses for digital imaging technologies over the course of the 1970s and 1980s, leading to a large-scale transition to raster display technology and along with it the rise of the modern computer screen. This transition from simple lines painted onto the face of a CRT to the pixelated bitmap that now structures almost all computer and television screens was thus made possible through this interfacing of image and memory that is the function of the frame buffer as a technical and visual medium.

\section{Pixel}

This brings us at last to our contemporary screen and that individual unit of screen memory: the pixel. Though nearly all contemporary screens comprise pixel-like elements arranged in a raster grid, the word was not widely used in computer graphics until the late 1970s. ${ }^{61}$ The word has many origins and can be traced back as far as the late-nineteenth-century German Bildpunkte, or "picture points," used in reference to photography and early cathode ray technology for television. ${ }^{62}$ The phrase "picture element" appears as early as 1927 in reference to television, and its abbreviation as pixel in 1965 as a reference to digital image processing for video and photography. The challenge in tracing the origin of the pixel as both a graphical object and technical term lies in its broad undifferentiated use across a wide range of imaging practices. Indeed the pixel has become an overburdened term for contemporary digital images as well, one that often obscures the specificity of the widely varying means by which 


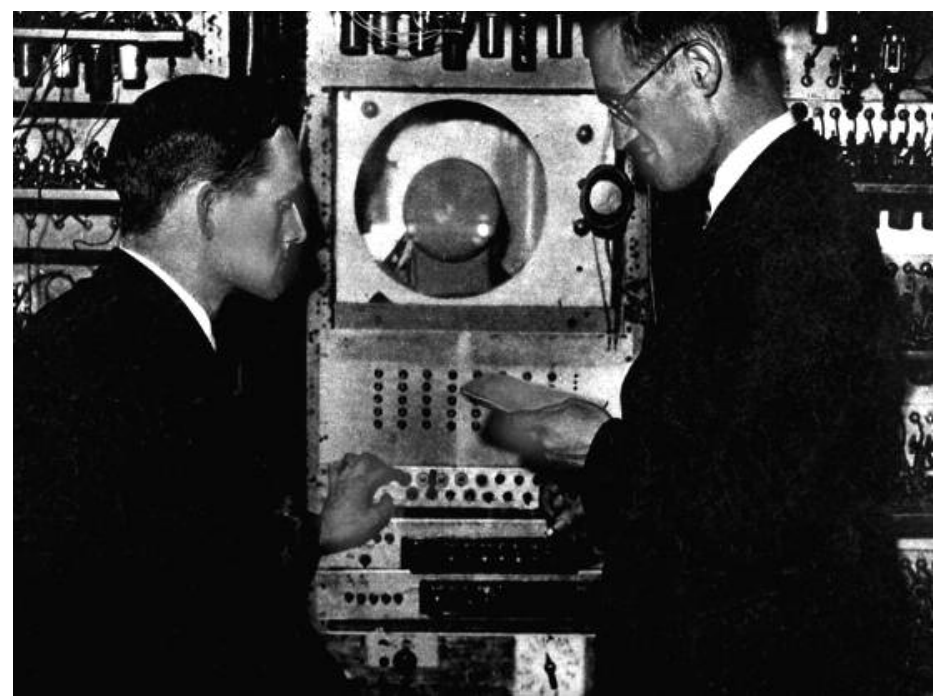

clarify the function the pixel serves.

As the smallest addressable element in an imaging system, the pixel functions as the most basic unit of that system. The pixel's clearest corollary in the computer itself is the binary digit or bit-the most basic unit of information in computing and digital communications-and at the earliest moment in the history of the modern computer, the two are one in the same. This is where the history of the computer screen begins, with a display known as the WilliamsKilburn tube.

In 1945 and 1946, the English engineer Freddie Williams paid two visits to the United States to assess the radar circuitry being developed there. ${ }^{63}$ On his second trip he made a visit to Bell Labs, where he saw several early experiments using CRTs for radar display. Bell technicians were seeking new ways to remove the ground echoes that occur in all radar systems, but Williams saw a different potential use for the CRT: as an electronic storage device for digital computing. ${ }^{64}$ At this early moment in the history of computing the field was undergoing dramatic changes in the theory and architecture of computational machines. While Alan Turing had developed the concept of universal computation ten years prior in 1936, not until 1945 would John von Neumann publish his foundational First Draft of a Report on the EDVAC. Drawing on the work of J. Presper Eckert and John Mauchly, von Neumann's text was the first to propose the stored program concept. ${ }^{65}$ Prior to this moment all computing machines had relatively fixed programs: They were capable of executing only the single computational program that was built into the design of the machine itself. Even those early computers that were programmable used physical forms of data storage such as punched tape or cards and had to be physically reprogrammed through switches in patch cords that took several days or weeks to complete. ${ }^{66}$ The key to von Neumann's stored program concept was its flexibility; it allowed for the transformation of instructions stored within the memory of a computer-but in 1945 it was little more than a theory. His report was explicitly ambiguous in describing the actual hardware required to make this theory function as part of a working machine, which led to several competing techniques for stored program computation, along with several competing claims for the first successful implementation of the stored program concept. ${ }^{67}$

In this early period most computers relied on relays, mechanical counters, or delay lines for their main memory functions, each of which had significant 


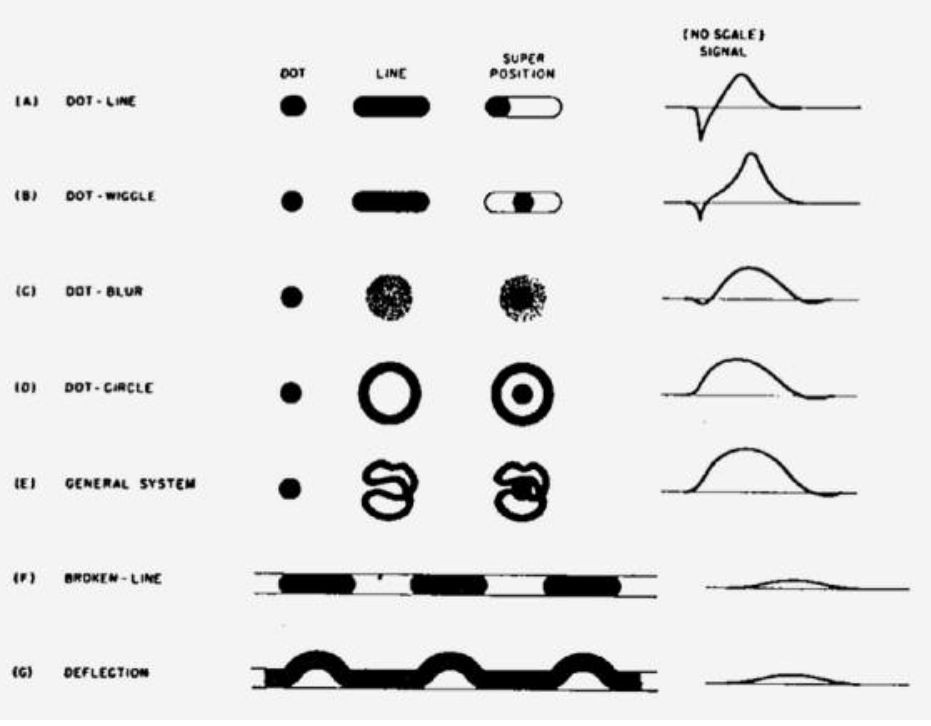

drawbacks in the efficient storage and retrieval of information. These early technologies had difficulty quickly storing and modifying data due to the sequential and fixed nature of their storage techniques. Delay line, for example, was developed in the 1920s as a technique to delay the propagation of analog signals and was used widely in radar technology during the Second World War. In the mid-1940s, Eckert modified delay lines to be used as computer memory, storing information in the delay through signal amplification. These sequential methods for computer memory functioned through repetition and were in this sense akin to the now antiquated technique of repeating a phone number to oneself from the time one finds it in the phone book until one has dialed it. ${ }^{68}$ The challenge of delay line memory was that reading or writing a particular bit required waiting for that bit to circulate completely through the delay line into the electronics. Thus, the ability for the device to access and transform information stored in the delay line was limited by the recirculation timea matter of microseconds. For a computing machine that sought to scale upward in both speed of access and size of storage, this was a significant limitation.

Williams believed the CRT could be used to develop a quicker and more efficient means of storing and transforming programs in computer memory for random access. To prove the viability of this method, a team of researchers at Manchester University began to build an experimental computing machine in late 1947. Some six months later they had developed the Manchester SmallScale Experimental Machine (SSEM)—also known as "Baby"—which successfully ran its first program on June 21, 1948, making it the world's first functional stored program machine. While the SSEM computer is most recognizable as the earliest successful implementation of the stored program concept, it was built largely to test the efficacy of Williams's theoretical CRT storage method. After proving their storage theory with the SSEM, researchers went on to transform the machine into a more usable computer in the Manchester Mark 1, which in turn became the prototype for the Ferranti Mark 1, the world's first commercially available general-purpose computer. In this sense one possible history of the modern general-purpose computer begins with the screen, though it is a screen that was never meant to be seen. Rather, it was one of the earliest devices for RAM, using a series of dots and dashes projected onto the screen of the CRT to store electrical charges that held binary data, a technique known as electrostatic storage.

The key to this electrostatic storage is a pair of otherwise undesirable properties of the phosphor used to coat the screens of a CRT. When electrons fired 


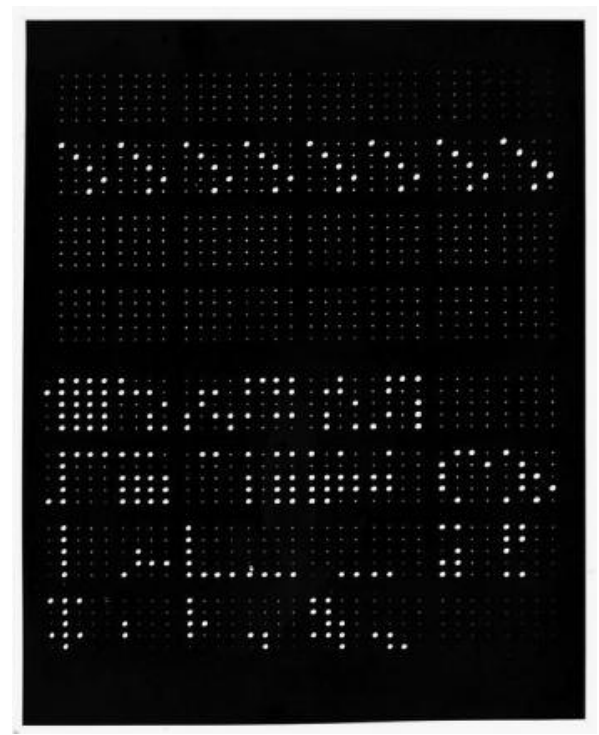

Opposite: A range of electrostatic storage patterns for binary storage. From J. Presper Eckert, "A Survey of Digital Computer Memory Systems," Proceedings of the Institute of Radio Engineers (1953).

Left: Williams-Kilburn tube face with dots and dashes of electrostatic bits. Courtesy the University of Manchester.

from a CRT's electron gun strike the phosphor coating of its screen, some electrons "stick" to the tube and cause an electrical charge to build up. This phosphor gives off additional electron particles when struck by an electron beam-a phenomenon known as secondary emission. The rate of release for these secondary particles is significantly nonlinear; that is, the rate of emission increases dramatically when a voltage is applied that crosses a certain threshold. This causes the lit spot of electrostatic charge to rapidly decay, releasing any stuck electrons in the process. This effectively allows the screen of the CRT to store two distinct electrostatic charge states controlled by the intensity of the electron gun: positive and negative, or 0 and 1. In this way the tube can be used to store binary data. In the case of the Williams-Kilburn tube, this appears as a grid of dots and dashes blinking across the face of its display. ${ }^{69}$ Each dot is an area of slightly positively charged electrons surrounded by an area of slightly negatively charged electrons, which acts as a charge well. The dot can be erased by drawing a second dot next to the first or by extending the dot into a short dash, thus filling in the charge well.

Importantly, these pixel-like dots and dashes are not merely the representation of binary data but the visible electrical state of the binary storage device itself. While screen images today may commonly be thought of as surface-level abstractions of some deeper technical language-be it code, binary, or even electrical signals - in this early moment the storage and representation of data are one in the same. Here the image does not simply represent the processing of data; it is that data in zeros and ones. What we see is not only an image but data itself; or rather it is image and data, indistinguishable and inseparable. Thus, the first example of a screen technology used in the history of computing is entirely nonrepresentational and even nonvisible, as these screens were meant to be covered or hidden from their operators by a special detector used to output data from memory. ${ }^{70}$ In this sense the Williams-Kilburn tube is exceptional in that it does not map onto the logic of interface or representation in the way that all subsequent screens do. In another sense, however, it is emblematic of all contemporary screens for its prototypical use of the pixel, the grid, and-most significant-the mapping together of image and memory.

While the Williams-Kilburn tube was the most successful and widely implemented electrostatic storage device, several other systems were simultaneously developed at research sites in the United States. ${ }^{71}$ As early as 1946, Vladimir Zworykin and Jan Rajchman began development of a working CRT memory at the Radio Corporation of America (RCA) for use by von Neumann at the Institute for Advanced Study in Princeton, New Jersey. Known as the Selectron 
Top: A Williams-Kilburn tube with open-face panel. Courtesy the University of Manchester.

Bottom: Williams-Kilburn tube with a 1,024-digit store image, University of Manchester, 1947. From F.C. Williams and T. Kilburn, "A Storage System for Use with Binary-Digital Computing Machines," Proceedings of the IEE-Part III: Radio and Communication Engineering (1949).

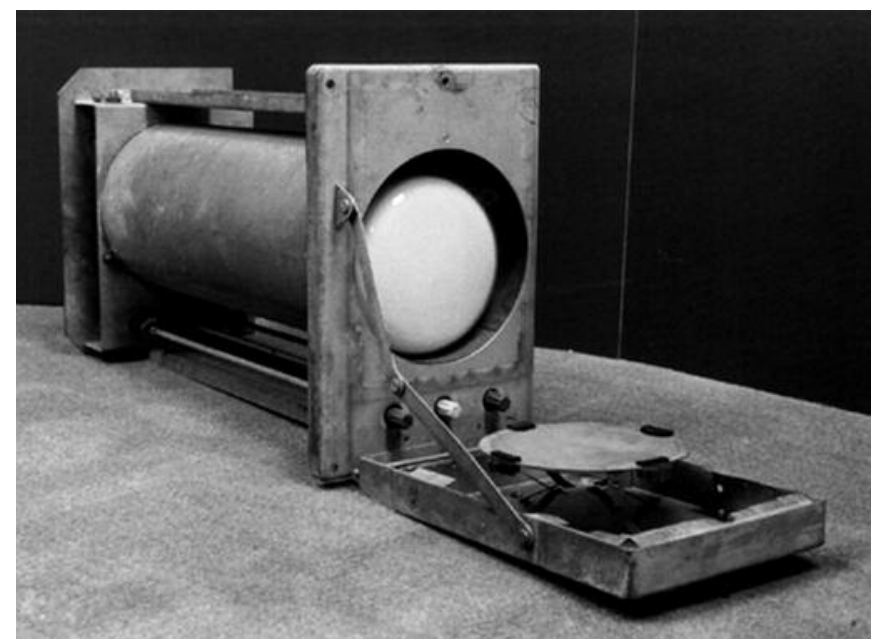

tube, it struggled in development and failed to be commercialized, such that its only use outside the IAS was in the RAND Corporation's JOHNNIAC computer. ${ }^{72}$ At MIT's Lincoln Laboratory, researchers began experimenting with the construction of stable electrostatic grids for use in the Whirlwind I computer as early as 1947, and by 1948 they had constructed a sixteen-by-sixteen grid of dots..$^{73}$ This number increased rapidly over the next three years, and by 1950 the lab was experimenting with 4,096 bits displayed as a massive grid of light on the screen of the CRT. ${ }^{74}$ To test the functionality of the Whirlwind storage tubes, researchers developed a program called Waves of One, which ran

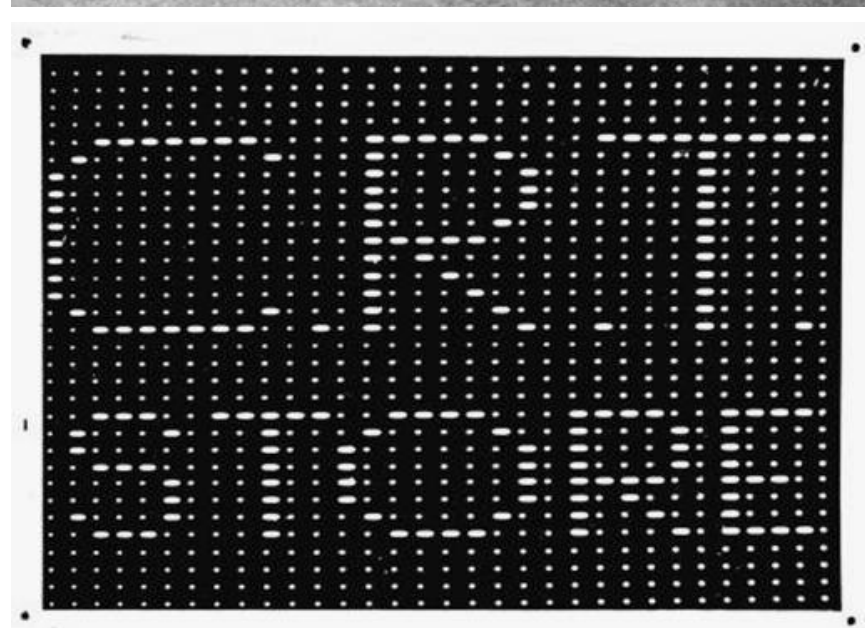

A C.R.T. DISPIAY - 1024 DIGITS

through each storage point on the screen, checking to ensure it was properly displayed. Norman Taylor, then the associate head of the computer division at Lincoln Lab, recalls this process of identifying individual points of light as the key moment in the development of graphical interaction. Referring to the Waves of One program, he notes,

If we read a one, the program continued, and if it didn't, it stopped. We were asking how we can identify the address of that spot. So Bob Everett, our technical director, said "we can do that easily." All we need is a light gun to put over the spot that stops and we'll get a readout as to which one it is. So he invented the light gun that afternoon and the next day we achieved man machine interactive control of the display-I believe for the first time. ${ }^{75}$

This affordance of the electrostatic storage tube to randomly access individual bits in memory also allowed for interactive manipulation with the light gun, switching on and off each point of light without recalculating the entire storage array. Taylor's anecdote demonstrates the way in which-even at this early stage-RAM was essential to the graphical manipulation of a raster grid. ${ }^{76}$

This brief but meaningful moment of contact between the visible image and its physical storage was quickly abstracted. As early as 1947 Williams and 


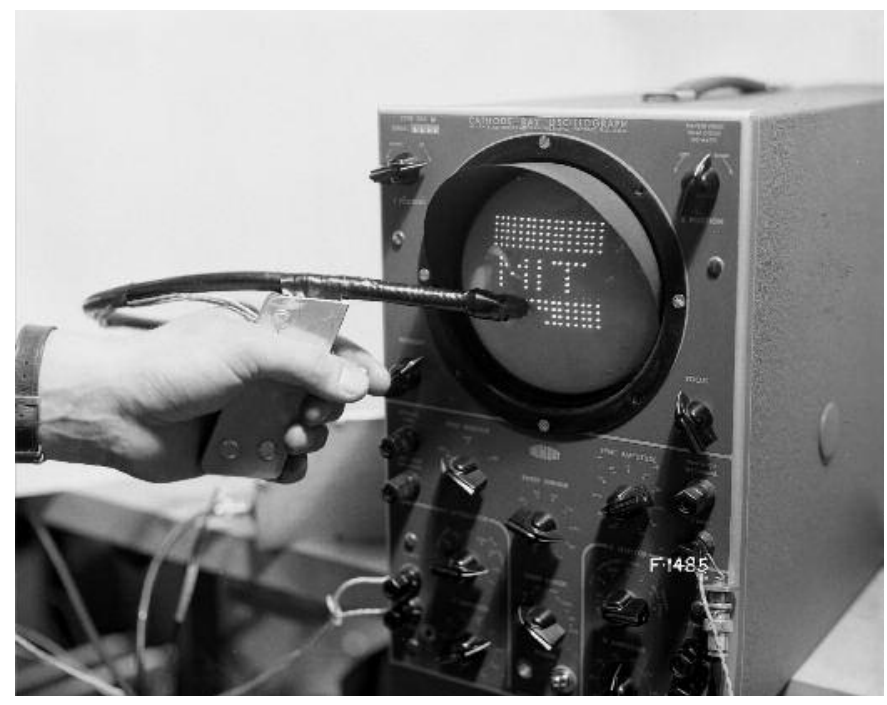

Carving out the MIT logo with an experimental electrostatic CRT, Massachusetts Institute of Technology, 1952. Courtesy the MITRE Corporation.

Kilburn began experimenting with their display as a representational interface, publishing a set of images alongside Kilburn's initial progress report to the Telecommunications Research Establishment on December 1, announcing "CRT STORE” in dots and dashes at 1,024 digits or bits. ${ }^{77}$ Likewise, researchers at MIT went on to perform graphical experiments using the storage tube, including carving out the letters MIT from the grid of lights. ${ }^{78}$ While these images were not intended for broad application, they nonetheless hinted at the technology's potential futures.

\section{RAM}

While the modern interactive screen with its pixelated raster and 32-bit color display is largely the outgrowth of a set of technologies developed in the 1970s, the use of screens for computation reaches back decades further to the very origins of the modern computer itself. One can say the modern computer begins with the screen, but as a device for memory and storage rather than as a representational display or interface. These early screens were a means of mapping the bits of the earliest digital computers in the phosphorescent glow of electricity and light, securing a connection between the screen and the material structure of the stored program computer that would repeat and reemerge throughout the history of computer graphics.

These early cathode ray techniques for electrostatic storage are important predecessors of modern-day graphical displays, but they represent a brief and largely failed experiment in the design of computer memory systems. Electrostatic storage was quick, but it was not stable or reliable over long periods of time. After only a few hours of use any electrostatic system would produce memory errors and need to be reset. Frustrated by the failure of their storage tube design, MIT researchers working on the Whirlwind I began experimenting with magnetic forms of storage, leading to the development of magnetic core memory in 1951. Magnetic core was the first reliable form of RAM, and remained an industry standard until it was displaced by solid-state memory in integrated circuits beginning in the early 1970s. With magnetic core, the bit state of a core memory plane was held on magnetized toroids woven into a grid of conductive wire. ${ }^{79}$ These wires formed contacts on each side of the plane, allowing for rapid and stable random-access manipulation of each toroid bit. While the material function of magnetic core systems diverges wildly from the electrostatic screen technology that preceded it, they notably adopt the grid form used in all previous random-access systems. Even contemporary 
integrated-circuit RAM chips, found in most all computational devices, are arranged

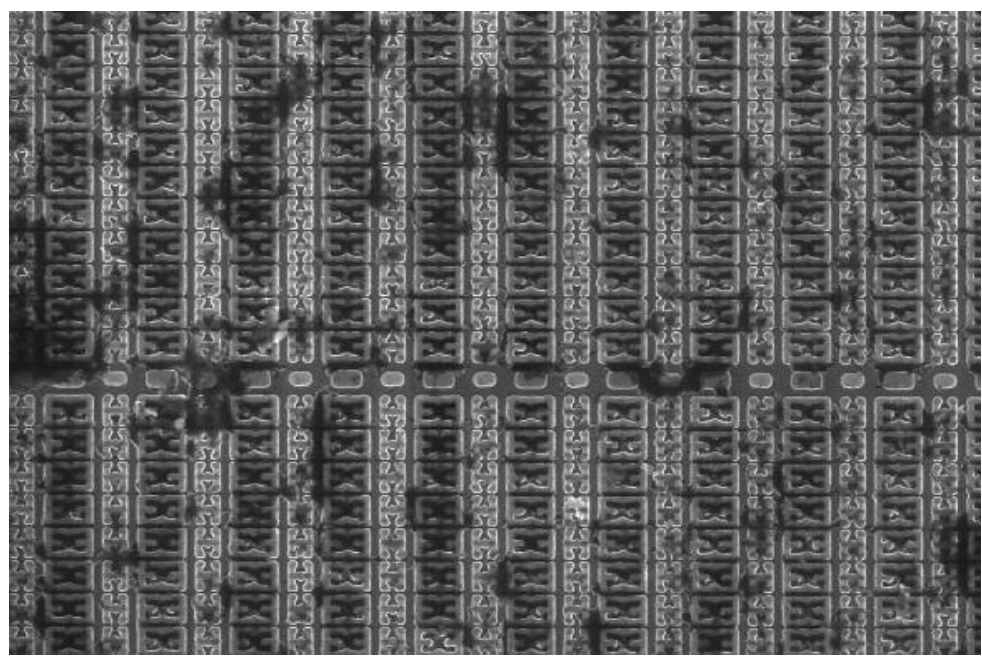

in a grid pattern on a microscopic level that mirrors these early random-access systems. This similarity is not incidental, as the grid's function is uniquely tied to the logic of random access-a logic that maps onto and can be traced through a variety of computational technologies that appear in the immediate postwar period and materially differentiate computer graphics from those screen technologies that precede it. Thus, the grid of computer graphics offers an ordering of the visible world such that it is made discrete and randomly accessibletransforming screen into memory, image into simulation.

Far from an inert surface on which the digital image appears, the computer screen is a unique media form as old as the modern computer itself. It is a deeply heterogeneous object, one that undergoes multiple transformations in its long history - at once line, grid, and pixel. Looking beyond these visual distinctions, what is most apparent is the endurance of memory as a structuring category that distinguishes computer graphics from earlier visual forms. By mapping the image into memory, computer graphics allow for random access to procedural vision, transforming the image from something that is captured and displayed into something that can be changed and manipulated, computed and interacted with. Through the grid of RAM a new image form takes shape, one that continues to dominate our visual culture some fifty years after its development. 


\section{Notes}

1. J. Presper Eckert Jr., "A Survey of Digital Computer Memory Systems," Proceedings of the IEEE 85, no. 1 (January 1997): 184. Originally published in Proceedings of the Institute of Radio Engineers 41 (October 1953): 1,393.

2. For a detailed analysis of contemporary screen technology, including contemporary pixel techniques for raster displays, see Sean Cubitt, The Practice of Light: A Genealogy of Visual Technologies from Prints to Pixels (Cambridge, MA: MIT Press, 2014), 95-100. Friedrich A. Kittler controversially discusses computer graphics from another perspective, that of the ontology of the pixel. See Friedrich A. Kittler, “Computer Graphics: A Semi-technical Introduction,” trans. Sara Ogger, Grey Room 2 (Winter 2001): 30-45.

3. Anne Friedberg, The Virtual Window (Cambridge, MA: MIT Press, 2009). See also the discussion of the screen and grid in Hubert Damisch, The Origin of Perspective, trans. John Goodman (Cambridge, MA: MIT Press, 1995); and Jonathan Crary, Techniques of the Observer (Cambridge, MA: MIT Press, 1992).

4. This biological metaphor is of central significance to the naturalization of technical imagery. See Vilém Flusser, Into the Universe of Technical Images (1986), trans. Nancy Ann Roth (Minneapolis: University of Minnesota Press, 2011), esp. 23-32; and Brandon Hookway, Interface (Cambridge, MA: MIT Press, 2014).

5. Nick Montfort, "Continuous Paper: The Early Materiality and Workings of Electronic Literature" (paper presented at the Modern Language Association Convention, Philadelphia, 28 December 2004), available at https://nickm.com/writing/essays/continuous_paper_mla.html. Most graphical output was likewise limited to point plotter drawings, used primarily for computer-aided design and in early experiments in computer art. See Christoph Klütsch, Computergrafik: Ästhetische Experimente zwischen zwei Kulturen: Die Anfänge der Computerkunst in den 1960er Jahren (Berlin: Springer, 2007).

6. Montfort, "Continuous Paper."

7. For a primer on the scanning principles at work in early television systems, see R.W. Burns, Television: An International History of the Formative Years (London: IEE in association with the Science Museum, 1998).

8. While all contemporary computer and television screens now function using a pixel-based raster grid, vector and raster graphic displays coexisted alongside one another well into the 1980s, with vector displays particularly prevalent in popular early arcade cabinets such as those used for Asteroids (1979), Star Castle (1980), and Lunar Lander (1980). Each technology produced its own set of affordances and limitations, and in turn each shaped the limits of what kinds of graphical images were possible. See Nick Montfort and Ian Bogost, "Random and Raster: Display Technologies and the Development of Video Games," IEEE Annals of the History of Computing 31, no. 3 (2009): 34-43.

9. On the early research into raster displays, see Jacob Gaboury, "Image Objects: An Archaeology of 3D Computer Graphics, 1965-1979” (Ph.D. diss., New York University, 2014); and H. Kent Bowen, “The University of Utah and the Computer Graphics Revolution” (case study, Harvard Business School, 28 April 2006). Interactive graphics predate the widespread commercialization of the frame buffer concept and were developed for programs such as Ivan Sutherland's Sketchpad as early as 1962. Nonetheless, these real-time interactive graphics were highly limited 
in their use and were restricted to the large-scale, multi-million-dollar computing machines on which they ran.

10. In this, Laposky follows in the long-standing tradition of "visual music" that reaches back to the start of the twentieth century. See Aimee Mollaghan, The Visual Music Film (London: Palgrave Macmillan, 2015); and Ben F. Laposky, Electronic Abstractions, exh. cat. (Cherokee, Iowa: Sanford Museum, 1953), 15.

11. Ben F. Laposky, “Oscillons: Electronic Abstractions,” Leonardo 2, no. 4 (October 1969), 348.

12. Laposky, "Oscillons," 352-353.

13. Randi Martin, "Laposky Cited for Tracing History in Computer Art," Cherokee Daily Times, 7 January 1972, 1; and Alison Drain, "Laposky's Lights Make Visual Music," Symmetry 4, no. 3 (April 2007): 33.

14. Most notable for her use of the oscilloscope is artist Mary Ellen Bute, but Laposky's work may also be understood more broadly in the history of computer art in both the United States and Europe. See Mary Ellen Bute, "Abstronics: An Experimental Filmmaker Photographs the Esthetics of the Oscillograph," Films in Review New York: National Board of Review of Motion Pictures 5 (1952): 263-266; and Hannah Higgins and Douglas Kahn, eds., Mainframe Experimentalism: Early Computation and Foundations of the Digital Arts (Berkeley, CA: University of California Press, 2012).

15. Of Laposky's original 102 mounted images, 101 remain in the collection of the Sanford Museum in Cherokee, Iowa. None of the 10,000 negatives Laposky claimed to have taken have been found, and he kept no records of the control settings he used to make them. While Laposky suggested the pieces could be displayed in any number of ways, including as active waveforms, much like Nam June Paik's cathode ray pieces such as TV Crown (1965), all that remains of the cathode ray sculptures are the photographs that document their initial form. For more on Paik's TV Crown, see "Nam June Paik, TV Crown (1965)," Fondation Daniel Langlois, http://www. fondation-langlois.org/html/e/media.php?NumObjet=71580.

16. By the year 2000, each U.S. household had an average of 2.43 television CRTs, not including computer screens and other CRT displays. "More Than Half the Homes in U.S. Have Three or More TVs," Nielsen, 20 July 2009, http://www.nielsen.com/us/en/insights/news/2009/morethan-half-the-homes-in-us-have-three-or-more-tvs.html.

17. The first flat-panel plasma display was developed by Donald L. Bitzer, H. Gene Slottow, and Robert Willson in 1964 at the University of Illinois Urbana-Champagne and was used in the PLATO computer system throughout the 1960s and 1970s. See Donald L. Bitzer and H.G. Slottow, "The Plasma Display Panel: A Digitally Addressable Display with Inherent Memory," in Proceedings of the November 7-10, 1966, Fall Joint Computer Conference (New York: ACM, 1966), 541-547; and Joy Rankin, "Toward a History of Social Computing: Children, Classrooms, Campuses, and Communities," IEEE Annals of the History of Computing 36, no. 2 (April-June 2014): 86-88.

18. In the late 1990s, CRTs were one of the largest sources of lead in municipal solid waste, leading numerous states in the early 2000s to ban their incineration or their disposal in landfills. See Hai-Yong Kang and Julie M. Schoenung, "Electronic Waste Recycling: A Review of U.S. Infrastructure and Technology Options," Resources, Conservation, and Recycling 45, no. 4 (December 2005): 368-400. The archiving of electronic images is also relevant here. For a para- 
digmatic discussion of preservation techniques for Paik's work, see John Anderson, "Nam June Paik: Preserving the Human Televisions," Art in America, 6 February 2013, http://www.artin americamagazine.com/news-features/news/nam-june-paik-smithsonian/.

19. For a useful primer on the life and death of the CRT, see Josh Lepawsky and Charles Mather, "A Terminal Condition: The Cathode Ray Tube's Strange Afterlife," The Atlantic, April 2014, http://www.theatlantic.com/technology/archive/2014/04/a-terminal-condition/361313/.

20. This is by necessity an oversimplification of this process, and ignores details such as video interlacing. Likewise the number of scan lines on a television set differs by region, and the history of scan line standardization is its own topic worthy of a separate history. The most prominent divergence is likely the incompatibility of NTSC (525 scan lines) and PAL (576 scan lines) standards. See Rosa Menkman, “The Collapse of PAL," Rhizome, 2010, http://rhizome.org/artbase/ artwork/54452/.

21. The ability to display an entire letter with a single projection of the electron beam allowed Charactron CRTs to display a relatively large amount of text. Charactron systems could display up to fifty characters horizontally at a rate of 10,000-20,000 characters per second. Due to the size of the CRT character matrix, each tube was limited to a specific set of sixty-four characters and shapes, though an operator could change fonts or character sets by physically removing and reinstalling a different tube-a process that took several minutes. See Peter A. Keller, The Cathode-Ray Tube: Technology, History and Applications (New York: Palisades Press, 1991); and Ben Ferber, "The Use of the Charactron with ERA 1103," in Proceeding AIEE-IRE '56 (Western): Papers Presented at the February 7-9, 1956, Joint ACM-AIEE-IRE Western Computer Conference (New York: ACM, 1956), 34-36.

22. The tube was most prominently used for the visual displays of the SAGE air defense system beginning in 1958 but was also the display that allowed for early graphical experiments using the Stromberg-Carlson 4020 computer at Bell Labs by artist-researchers including A. Michael Noll, Lillian Schwartz, and Kenneth Knowlton. For more on the SAGE system, see Paul N. Edwards, The Closed World: Computers and the Politics of Discourse in Cold War America (Cambridge, MA: MIT Press, 1997). For a discussion of SAGE in the context of midcentury artistic and visual cultures in the U.S. and Canada, see Kenneth White, "Strangeloves: From/De la région centrale, Air Defense Radar Station Moisie, and Media Cultures of the Cold War," Grey Room, no. 58 (Winter 2015): 50-83. For a detailed study of the Stromberg Carlson 2040 and early graphical experimentation at Bell Labs, see Zabet Patterson, Peripheral Vision: Bell Labs, the SC 4020, and the Origins of Computer Art (Cambridge, MA: MIT Press, 2015).

23. While in the United States we continue to use Vladimir Zworykin's term cathode ray tube, it is called the Braunsche Röhre (Braun tube) in German-speaking countries and Buraun-kan in Japan.

24. See R.W. Burns, Television: An International History of the Formative Years (London: Institution of Engineering and Technology, 1997); Albert Abramson, Zworykin, Pioneer of Television (Chicago: University of Illinois Press, 1995); and Albert Abramson, The History of Television, 1880 to 1941 (London: McFarland, 1987).

25. While the cathode ray oscilloscope would become the most prominent technical form oscillography would take, the visualization of waveforms was accomplished early on through a wide range of techniques, from hand-plotting and automated paper drawing to photography and 
mirrored projection. See Nehemiah Hawkins, Hawkins Electrical Guide (New York: Theodore Audel, 1914).

26. The other widely influential and historically significant use of the CRT during this period was in radar display, beginning with the work of meteorologist Robert Watson-Watt in 1923. Radar technology existed prior to this moment, but the widespread use of radar displays in World War II is one explanation for their adoption by war-trained engineers for computer graphics in the postwar period. For work on the history of radar, see Jim Brown, Radar: How It All Began (Cambridge, UK: Janus Publishing, 1996); Robert Buderi, The Invention That Changed the World: How a Small Group of Radar Pioneers Won the Second World War and Launched a Technical Revolution (New York: Simon \& Schuster, 1996); S.S. Swords, Technical History of the Beginnings of Radar (London: Institute of Engineering and Technology, 1986); and Louis Brown, A Radar History of World War II: Technical and Military Imperatives (Bristol, UK: Institute of Physics Publishing, 1999).

27. Early vector display systems were often modified oscilloscope displays, but later custom vector displays used magnetic force to move and shift the direction of the electron beam and were widely used in arcade cabinets and other display technologies throughout the 1970s and 1980s. Montfort and Bogost, 35.

28. Specialized circuits were required to convert the digital signals of these early computers into analog signals for calligraphic display. See Ivan Sutherland, "Computer Displays," Scientific American 222, no. 6 (1970): 60.

29. In digital imaging and computer graphics, aliasing is the appearance of distortion artifacts when representing a high-resolution image at a lower resolution or when displaying curved or irregular shapes on a raster screen. Antialiasing techniques are used to minimize these effects, the results of which are often referred to as "jaggies" for their jagged, steplike appearance.

30. In contrast, storage-tube vector-graphics terminals were designed to maintain a single image on screen without the need to refresh the beam, thereby avoiding the problem of image flicker. Many storage-tube vector systems used two electron guns: one to draw the image and another to "bathe" the entire screen with electrons at a lower intensity, preserving its screen image indefinitely. This limited the screen's utility, however, because in order to erase any part of an image the entire screen would need to be cleared. This made storage-tube systems less popular with CGI researchers.

31. The goal for computer graphics from its initial formalization by the U.S. Department of Defense in the mid-1960s included realistic shading, lighting, and object opacity, along with fully interactive screen images-all of which would require raster display technology. These stated goals are outlined in internal and public-facing publications of the period, including Advanced Research Projects Agency, “Graphic Control and Display of Computer Processes," program plan no. 439, 1 March 1965, in National Archives Branch Depository, record group (RG) 330-78-0013, box 1, folder: "Program Plans"; Robert W. Taylor, "Accomplishments in Calendar Year 1967, Internal Memorandum for the Acting Deputy Director, ARPA," 5 January 1968, pp. 2-3, in National Archives Branch Depository, RG 330-74-107, box 1, folder: "Internal Memoranda 1968 through 1970"; Sutherland, "Computer Displays"; Frank D. Skinner, "Computer Graphics: Where Are We?” Datamation 12 (May 1966): 28-31; and J.C.R. Licklider, “Computer Graphics as a Medium of Artistic Expression," in Computers and Their Potential Application in Museums (New York: 
Arno, 1968).

32. For Bernhard Siegert the grid is one of many cultural techniques (Kulturtechniken) that reproduce, displace, process, and reflect the distinctions fundamental to a given culture over time. See Bernhard Siegert, "(Not) in Place: The Grid, or, Cultural Techniques of Ruling Spaces," in Cultural Techniques: Grids, Filters, Doors, and Other Articulations of the Real (New York: Fordham University Press, 2015), chap. 6.

33. Hannah Higgins, The Grid Book (Cambridge, MA: MIT Press, 2009).

34. Rosalind Krauss, "Grids," October 9 (Summer 1979): 50-64.

35. Krauss, "Grids," 50.

36. Higgins, 6 .

37. Siegert, 98, quoting Michel Foucault, "Why Study Power: The Question of the Subject," in Beyond Structuralism and Hermeneutics, ed. Hubert L. Dreyfus and Paul Rabinow (Chicago: University of Chicago Press, 1982), 208.

38. In contrast, cinema's ability to sample and store time in discrete form (twenty-four frames per second) arguably positions it more closely with the temporality of the digital. See Lev Manovich, The Language of New Media (Cambridge, MA: MIT Press, 2001), 50-51.

39. This problem does not disappear with the introduction of the frame buffer, as the analog form of the electron beam in any CRT display requires the conversion of digital information into analog signal for output and visualization. See Sutherland, "Computer Displays," 60.

40. As Ivan Sutherland notes, "The calligraphic display has the advantage that information to be displayed can be stored in computer memory in any order, whereas information for a raster display must first be sorted from top to bottom and from left to right so that it can be put on screen in the correct sequence. . . . The task of sorting information from top to bottom and from left to right for presentation on raster displays has largely precluded their use for anything but presentations of text. In principal, however, a raster display has the potential of producing pictures with a range of light and dark tones, in color if desired, that provide a realism unequalled by the line drawings of a calligraphic display." Sutherland, "Computer Displays," 57.

41. Bitmap is a general term for the mapping of some domain into bits. In computer graphics a bitmap gives a way to store the location of a binary image, though a true bitmap image has only two bit settings, 0 or 1, black or white. Pixmap refers to a map of pixels where each pixel may store more than two colors and thereby more than one bit per pixel. The term bitmap is sometimes used for all pixelated bit mapping, but at this early moment it was not possible to map a full range of colors into a pixmap, so the distinction is of little significance.

42. Alvy Ray Smith, "Digital Paint Systems: An Anecdotal and Historical Overview," IEEE Annals of the History of Computing 23, no. 2 (April-June 2001), 12.

43. "The discrete, or digital, nature of both the geometric coordinates and their chromatic values makes possible the magical artifice that separates computer graphics from film and television. Now, for the first time in the history of optical media, it is possible to address a single pixel in the 849th row and 720th column directly without having to run through everything before and after it." Kittler, 32.

44. Miller is best known for her work with Max Matthews on the digital synthesis of sound, which led in 1961 to a fully synthesized version of the song "Daisy Bell"-also known as "Bicycle Built for Two"- that so inspired Arthur C. Clark on a visit to Bell Labs that he incorporated it into 
his novel 2001: A Space Odyssey. Joan Miller, personal communication with Alvy Ray Smith, Bell Labs, Murray Hill, NJ, July 1978, cited in Alvy Ray Smith, "Tint Fill," ACM SIGGRAPH Computer Graphics 13, no. 2 (1979): 276-283. On the development of one of the earliest experimental frame-buffer systems, known as the Brookhaven Raster Display (BRAD), see D. Ophir et al., "BRAD: The Brookhaven Raster Display," Communications of the ACM11, no. 6 (June 1968): 415.

45. Noll and others at Bell Labs had worked in the early 1960s to produce raster graphics via the BEFLIX programming language, but these were not real-time graphics intended to be seen and interacted with on the display of a CRT. Rather they were filmed off a special CRT device and viewed later as film projections. See Patterson.

46. A. Michael Noll, "Scanned-Display Computer Graphics," Communications of the ACM14, no. 3 (March 1970): 146-148.

47. When discussing most computer graphics systems, one generally needs to consider five bit depths: 1-bit, 3-bit, 8-bit, 24-bit, and 32-bit. These correspond, respectively, to 2 colors (black and white), 8 colors, 256 colors, 16.7 million colors, and 16.7 million colors plus 256 levels of transparency. The 8-bit, or 256-color, systems made digital painting a real tool for color video and general artistic applications. The 24-bit and 32-bit paint systems are required for higher-quality film use. The difference between 24-bit and 32-bit systems is the availability of an extra channelthe "alpha channel"- that always carries transparency information for all images.

48. The hardware for the initial frame buffer took up three refrigerator-size racks and cost almost a quarter of a million dollars. Smith, "Digital Paint Systems," 5, 12.

49. Richard Shoup, "SuperPaint: An Early Frame Buffer Graphics System," IEEE Annals of the History of Computing 23, no. 2 (April-June 2001): 34.

50. This failed vision was one of many prominent mistakes made by Xerox during this period, during which it developed and failed to commercialize numerous contemporary technologies, including the personal computer itself. See Douglas K. Smith and Robert C. Alexander, Fumbling the Future: How Xerox Invented, then Ignored, the First Personal Computer (New York: William Morrow and Company, 1988).

51. James Kajiya, Ivan E. Sutherland, and Edward C. Cheadle, "A Random-Access Video Frame Buffer," in Proceedings of the IEEE Conference on Computer Graphics (Piscataway, NJ: IEEE, 1975), 1-6.

52. This period marks the earliest instance of experimentation with pixel resolution for rendered objects. Chris Wylie et al., "Half-Tone Perspective Drawings by Computer," in Proceedings of the November 14-16, 1967, Fall Joint Computer Conference (New York: ACM, 1967), 49-58.

53. Jacob Gaboury, "Hidden Surface Problems: On the Digital Image as Material Object," Journal of Visual Culture 14, no. 1 (2015): 40-60.

54. Only one year later, at the International Federation for Information Processing conference in Edinburgh, a team of researchers presented a paper demonstrating a dramatic increase in the range and quality of three-dimensional rendered objects, though computation and display time was still on the order of several dozen seconds per image. Gordon Romney, Gary Watkins, and David Evans, "Real-Time Display of Computer Generated Half-Tone Perspective Pictures," in Information Processing 68: Proceedings of IFIP Congress 1968, Edinburgh, UK (Laxenburg, Austria: IFIP, 1968), 973-978.

55. Color images could be achieved using a color map, which simulated 24-bit color depth on 
an 8-bit system using a color look-up table.

56. While the department had limited funding for visiting artists, one faculty member's work was dedicated exclusively to artistic applications of computer graphics: the paper-folding artist and architect Ronald Resch. See Ronald D. Resch, "The Topological Design of Sculptural and Architectural Systems," in Proceedings of the June 4-8, 1973, National Computer Conference and Exposition (New York: ACM, 1973), 643-650.

57. Smith, "Digital Paint Systems," 14.

58. Schure was deeply invested in being the first to develop a fully digital animated film and thus often asked his research team what they needed to stay ahead. Not long after acquiring the first E\&S frame buffer, Smith told Schure in passing that what they really needed was two additional frame buffers to assemble a true RGB buffer. This would allow them to produce true dynamic color range with full antialiasing. Within several weeks Schure had purchased not two but five additional buffers at $\$ 60,000$ each. Combined with the original buffer, they made for $\$ 360,000$ spent on little more than an offhand request, the contemporary equivalent of more than $\$ 1,600,000$. This made NYIT the first studio capable of producing images in full 24-bit color. Alvy Ray Smith, interview by author, Berkeley, CA, 20 August 2012.

59. Schure's animation team initially produced a feature-length adaptation of Paul Tripp's "Tubby the Tuba" using conventional animation methods, though it was poorly received and a commercial flop. Following this failure, Schure looked to computational techniques to reduce expenses and streamline production. See Edwin Catmull, "The Problems of Computer-Assisted Animation," ACM SIGGRAPH Computer Graphics 12, no. 3 (1978): 348-353; and Tubby the Tuba, directed by Alexander Schure (Los Angeles, CA: Embassy Pictures, 1975), 35 mm.

60. For more on the history of Pixar, see David Price, The Pixar Touch: The Making of a Company (New York: Vintage, 2009).

61. Edwin Catmull, "Computer Display of Curved Surfaces," in Proceedings of the IEEE Conference on Computer Graphics, Pattern Recognition, and Data Structures, Los Angeles, May 1975, reprinted in Rosalee Wolfe, ed., Seminal Graphics: Pioneering Efforts That Shaped the Field (New York: ACM, 1998).

62. The term is used in Paul Nipkow's 1884 patent for his mechanical-scanning television and by Hermann Voge (1874) in reference to the point in the focal plane of a camera lens where rays from an object point converge. See Richard F. Lyon, "A Brief History of 'Pixel,"” reprint, paper E1 6069-1, Digital Photography II, IS\&T/SPIE Symposium on Electronic Imaging, San Jose, CA (January 2006); and Richard Lyon, "Pixels and Me" (lecture, Computer History Museum, 23 March 2005), available online at Computer History Museum, "Pixels and Me, lecture by Richard Lyon," Youtube, https://youtu.be/D6n2Esh4jDY. For an alternate history of the pixelated image in nineteenth-century painting, see Carol Armstrong, "Seurat's Media, or a Matrix of Materialities," Grey Room 58 (Winter 2015): 6-25.

63. Tom Kilburn, "Mark I" (presentation, Manchester Science Museum, 23 May 1991), reported in "Early Computers at Manchester University," Computer Resurrection: The Bulletin of the Computer Conservation Society 1, no. 4 (Summer 1992), http://www.cs.man.ac.uk/CCS/ res/res04.htm\#g.

64. As Smith notes in his history of early memory tube technology, Kilburn's initial account of the development of the CRT memory concept attributes its invention to the Radiation Laboratory 
at MIT. Only later does he suggest that the visit merely served as inspiration for Williams's own invention. See Alvy Ray Smith, "The Dawn of Digital Light," IEEE Annals of the History of Computing 38, no. 4 (2016): 74-91; and Tom Kilburn, "A Storage System for Use with Binary Digital Computing Machines" (report submitted to Telecommunications Research Establishment, December 1947), School of Computer Science, University of Manchester, http://curation.cs. manchester.ac.uk/computer50/www.computer50.org/kgill/mark1/report1947cover.html.

65. John von Neumann, “The First Draft Report on the EDVAC,” 30 June 1945, available at John R. Harris, Virtual Travelog, http://www.virtualtravelog.net/wp/wp-content/media/2003-08TheFirstDraft.pdf. Von Neumann was not alone in developing the idea of stored-program architecture. While he is most often credited with the concept, many computer historians consider it inaccurate to refer to electronic stored-program digital computers as "von Neumann machines" because of the significant contributions of figures such as Turing, Konrad Zuse, Eckert, and Mauchly. See Jack Copeland, “A Brief History of Computing: ENIAC and EDVAC” (June 2000), Turing Archive for the History of Computing, http://www.alanturing.net/turing_archive/ pages/reference\% 20articles/briefhistofcomp.html\#ENIAC; and B. Randell, "On Alan Turing and the Origins of Digital Computers," in Machine Intelligence 7, ed. B. Meltzer and D. Michie (Edinburgh: Edinburgh University Press, 1972), 10.

66. These include the Z3 (Germany, 1941), the Harvard Mark 1 (USA, 1944), and the ENIAC (USA, 1946).

67. Wendy Chun describes this not as an omission but as an intentional methodological decision on the part of von Neumann, suggesting it reflects the "axiomatic" (blackboxing) method of his general theory of natural and artificial automata as well as his work on game theory. See Wendy Chun, Programmed Visions: Software and Memory (Cambridge, MA: MIT Press, 2011), 133.

68. Eckert describes this process technologically as a "short-range human device" for memory. See Eckert, "Digital Computer Memory Systems,” 186.

69. One likely outgrowth of the blinking lights of the Williams-Kilburn CRT is the "blinkenlights" effect of early mainframe computers, in which blinking lights were used to indicate the computer was working and had not ceased to function. Very early computers tended to fail midcomputation. To show whether the machine was working, a set of lights was sometimes added that indicated the condition of the address bus, data bus, and (sometimes) the control bus. If the lights were blinking, the computer was doing something. If the lights stopped in a pattern, the computer had stopped doing anything, and the problem might be found at the binary address displayed by the lights. These displays were useful because many programs might take days to complete, and the outcome would be known only when the machine spat out a card with an eighty-character answer. While the lights became quickly outdated as technology improved, they often remain as a skeuomorphic indication of computation in action. See "Blinkenlights," The Jargon File, version 4.4.6, 25 October 2003, http://jargon-file.org/archive/jargon-4.4.6.dos.txt.

70. Nonetheless, many systems used an additional CRT as an output device that could display the results of a calculation or the image from any of its storage tubes as a binary array. Researchers could physically view the bits of data stored in the machine at any given time to determine the state of a calculation or to debug a program that failed to run. Turing termed this visual inspection "peeking," and PEEK and POKE are still used as commands in the BASIC programming language to read and set the contents of a memory cell at a specified address. Matthew G. 
Kirschenbaum, Mechanisms: New Media and the Forensic Imagination (Cambridge, MA: MIT Press, 2008), 254-256.

71. As early as 1945, Eckert developed but failed to implement an electronic CRT memory, writing bits to a screen but failing to read or keep them refreshed for use in computation. Perhaps the earliest CRT developed for both memory and picture display was the Haeff tube, developed in 1947 by Andrew V. Haeff while working at the U.S. Naval Research Laboratory in Washington, DC; it was the first tube able to store and display graphics and text on an electronic screen for an unlimited period of time. See J.P. Eckert Jr., H. Lukoff, and G. Smoliar, "A Dynamically Regenerated Electrostatic Memory System," Proceedings of the IRE 38 (1950) 498-510. This is a revision of the talk presented at the 1949 IRE Convention on 8 March 1949 in New York. See also B. Jack Copeland et al., "Screen History: The Haeff Memory and Graphics Tube," IEEE Annals of the History of Computing 39, no. 1 (2017): 9-28.

72. Fred Joseph Gruenberger, The History of the Jonniac, Memorandum RM-5654-PR (RAND Corporation, October 1968), 25-27.

73. Recent research by Smith calls into question the dates ascribed to this work at MIT, as the images Taylor used to illustrate the working of the Whirlwind tubes appear to be from 1952. See Smith, "The Dawn of Digital Light."

74. Jan Hurst et al., "Retrospectives I: The Early Years in Computer Graphics at MIT, Lincoln Lab and Harvard," in SIGGRAPH '89 Panel Proceedings: July 31-August 4, 1989 (New York: ACM, 1989).

75. Hurst et al., "Retrospectives I," 20.

76. For a detailed account of the Whirlwind I computer, see Kent C. Redmond and Thomas M. Smith, Project Whirlwind: History of a Pioneer Computer (Bedford, MA: Digital Press, 1980).

77. This was followed slightly later by a "2048 DIGIT STORE" image at twice the resolution. Unlike the research team at MIT, however, Williams and Kilburn's team made no further efforts to research graphical representation. F.C. Williams and T. Kilburn, "A Storage System for Use with Binary-Digital Computing Machines," Proceedings of the IEE—Part III: Radio and Communication Engineering 96, no. 40 (1949): 82.

78. Hurst et al., "Retrospectives I," 22.

79. The weaving of these planes was often the work of female technicians, as was the wiring of circuits and other manual technical labor. See Sadie Plant, Zeros and Ones: Digital Women and the New Technoculture (New York: Doubleday, 1997); and Lisa Nakamura, "Indigenous Circuits: Navajo Women and the Racialization of Early Electronic Manufacture," American Quarterly 66, no. 4 (December 2014): 919-941. 